\title{
Episodes of cross-polar transport in the Arctic troposphere during July 2008 as seen from models, satellite, and aircraft observations
}

\author{
H. Sodemann ${ }^{1}$, M. Pommier ${ }^{2}$, S. R. Arnold ${ }^{3}$, S. A. Monks ${ }^{3}$, K. Stebel ${ }^{1}$, J. F. Burkhart ${ }^{1}$, J. W. Hair ${ }^{4}$, G. S. Diskin ${ }^{4}$, \\ C. Clerbaux ${ }^{2,5}$, P.-F. Coheur ${ }^{5}$, D. Hurtmans ${ }^{5}$, H. Schlager ${ }^{6}$, A.-M. Blechschmidt ${ }^{7}$, J. E. Kristjánsson ${ }^{7}$, and A. Stohl ${ }^{1}$ \\ ${ }^{1}$ Norwegian Institute for Air Research (NILU), Kjeller, Norway \\ ${ }^{2}$ UPMC Univ. Paris 06, Université Versailles St-Quentin, CNRS/INSU, LATMOS-IPSL, Paris, France \\ ${ }^{3}$ Institute for Climate and Atmospheric Science, School of Earth and Environment, University of Leeds, Leeds, UK \\ ${ }^{4}$ Atmospheric Sciences, NASA Langley Research Center, Hampton, Virginia, USA \\ ${ }^{5}$ Spectroscopie de l'Atmosphère, Chimie Quantique et Photophysique, Université Libre de Bruxelles, Brussels, Belgium \\ ${ }^{6}$ Deutsches Zentrum für Luft- und Raumfahrt, Institut für Physik der Atmosphäre, Oberpfaffenhofen, Germany \\ ${ }^{7}$ Department of Geosciences, University of Oslo, Oslo, Norway
}

Received: 22 October 2010 - Published in Atmos. Chem. Phys. Discuss.: 5 November 2010

Revised: 25 March 2011 - Accepted: 29 March 2011 - Published: 19 April 2011

\begin{abstract}
During the POLARCAT summer campaign in 2008, two episodes (2-5 July and 7-10 July 2008) occurred where low-pressure systems traveled from Siberia across the Arctic Ocean towards the North Pole. The two cyclones had extensive smoke plumes from Siberian forest fires and anthropogenic sources in East Asia embedded in their associated air masses, creating an excellent opportunity to use satellite and aircraft observations to validate the performance of atmospheric transport models in the Arctic, which is a challenging model domain due to numerical and other complications.
\end{abstract}

Here we compare transport simulations of carbon monoxide (CO) from the Lagrangian transport model FLEXPART and the Eulerian chemical transport model TOMCAT with retrievals of total column $\mathrm{CO}$ from the IASI passive infrared sensor onboard the MetOp-A satellite. The main aspect of the comparison is how realistic horizontal and vertical structures are represented in the model simulations. Analysis of CALIPSO lidar curtains and in situ aircraft measurements provide further independent reference points to assess how reliable the model simulations are and what the main limitations are.

The horizontal structure of mid-latitude pollution plumes agrees well between the IASI total column CO and the model simulations. However, finer-scale structures are too quickly

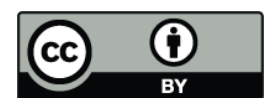

Correspondence to: H. Sodemann (hso@nilu.no) diffused in the Eulerian model. Applying the IASI averaging kernels to the model data is essential for a meaningful comparison. Using aircraft data as a reference suggests that the satellite data are biased high, while TOMCAT is biased low. FLEXPART fits the aircraft data rather well, but due to added background concentrations the simulation is not independent from observations. The multi-data, multi-model approach allows separating the influences of meteorological fields, model realisation, and grid type on the plume structure. In addition to the very good agreement between simulated and observed total column CO fields, the results also highlight the difficulty to identify a data set that most realistically represents the actual pollution state of the Arctic atmosphere.

\section{Introduction}

The polar regions of the northern hemisphere are often perceived as remote and pristine. However, atmospheric transport can swiftly bring pollution from emission sources at lower latitudes to the Arctic. Until recently, it was a commonly accepted view that air pollution continuously seeps into the Arctic, similar to a bathtub filling up slowly from a dripping faucet (Raatz and Shaw, 1984; Barrie, 1986). Recent research has replaced this concept by a picture where synoptic-scale events lead to the rapid advection of polluted mid-latitude air that is subsequently assimilated into the cold

Published by Copernicus Publications on behalf of the European Geosciences Union. 
Arctic air mass through radiative cooling (Stohl, 2006). One implication of the dripping faucet hypothesis was the view of the Arctic as a more or less homogeneous, well-mixed air mass with so-called background levels of atmospheric pollutants. Observations from aircraft and more recently aerosol lidar have however demonstrated repeatedly since the 1980s that the stably stratified Arctic air mass consists of an inhomogeneous, finely stirred mélange of layered air masses with different physical and chemical properties that only slowly undergoes mixing (Engvall et al., 2008, 2009).

The reason for the fine layering of the Arctic atmosphere lies in its thermal stratification. The lower part of the Arctic troposphere, the so-called polar dome, is isolated from the rest of the atmosphere due to its low potential temperatures (Klonecki et al., 2003; Stohl, 2006). Towards its southern boundaries this cold airmass creates an apparent horizontal transport barrier, which enhances the concentration gradients between the mid-latitudes and the Arctic. It should be noted that while to a first order the Arctic front apparently hinders pollution transport into the Arctic (Barrie, 1986) it is also the region of baroclinic development that ultimately leads to the poleward advection of mid-latitude air as part of frontal systems. Within the Arctic dome, transport and exchange are particularly slow and long residence times ensue. As air masses move towards the pole they are radiatively cooled, and become incorporated into a region of large vertical gradient of potential temperature. Layers of different age and origin are stacked on top of one another and are only slowly incorporated into the Arctic dome by further radiative cooling, mixing and diffusion. In contrast, above the polar dome residence times can be on the order of only a few days (Klonecki et al., 2003; Stohl, 2006).

The fine-scale structure of the Arctic atmosphere poses a major problem for atmospheric transport model simulations. Computational constraints require that Eulerian grid models are commonly run at horizontal and vertical resolutions that are inadequate for representing the actual structure of the Arctic atmosphere. This leads to the overly rapid diffusion and decay along the boundaries of advected plumes (Rastigejev et al., 2010). Another common problem in Eulerian models using a latitude-longitude grid is that the convergence of the meridians towards the poles leads to a singularity that needs to be accommodated by specific numerics. While in most models measures are taken to ensure numerical stability near the pole, such as decreasing the grid resolution, subdividing the time step (Krol et al., 2005) or changing the advection scheme around the pole, side-effects like reduced effective resolution or enhanced numerical diffusion cannot be avoided. These side-effects counteract the requirement that numerical diffusion should be small to retain the sharp gradients in stable air masses (Krol et al., 2005). Other approaches such as calculations on an icosahedral grid are not yet widely used (Thuburn, 1997). Another common approach to atmospheric transport modeling is Lagrangian modelling. Lagrangian transport models cal- culate the advection of individual air parcels based on threedimensional wind fields. A major advantage of these models is that in principle they are not limited by grid resolution. Unlike Eulerian chemistry transport models (CTMs), most Lagrangian models are currently not capable of simulating the chemical transformation of an air mass. Also, due to issues with mass distribution, Eulerian models are so far better suited to perform global budget studies and simulations over long timescales. To some extent, Lagrangian models may also be affected by numerical problems near the pole as the meteorological data which force them are calculated by $\mathrm{Eu}-$ lerian models. The long transport pathways, long lifetimes of pollutants in the cold Arctic air, and strong vertical temperature gradients close to the surface (Strunin et al., 1997) are further challenges for all atmospheric transport calculations in polar regions. To our knowledge, simulations of transport in the Arctic atmosphere from both model types have not yet been compared directly.

In addition to numerical difficulties, simulations in the Arctic are restricted by the sparsity of observational data. Routine meteorological surface observations for example that are assimilated into meteorological data used by transport model simulations are less dense in the Arctic. Furthermore, it is difficult to obtain reliable data for validating model simulations in this region. Passive and active remote sensing, for example from satellites, is hampered by low solar zenith angles and the reflective and thermal properties of the surface (Turquety et al., 2009). Another difficulty is that emission sources are mostly located far outside the Arctic, and are often not well quantified. Most of the emission sources that affect the Arctic are located in Europe, Eurasia and other mid-latitude areas (Stohl, 2006). The source region influence is subject to a pronounced seasonal cycle. During winter, emissions from fossil fuel and biofuel combustion and industrial processes constitute the main sources. During spring and summer pollution sources are forest fires and other biomass burning as well as industrial emissions (Stohl et al., 2007; Warneke et al., 2009; Paris et al., 2009; Warneke et al., 2010).

Taking technical and observational problems together, it is not surprising that a recent inter-comparison study between 17 CTMs for the Arctic mainly highlighted the disagreement between model results, e.g. with respect to the simulated seasonal cycle of atmospheric constituents (Shindell et al., 2008). Models also disagree on the role and distance of pollution sources. While Koch and Hansen (2005) argued for a large contribution from South Asia to black carbon concentrations in the Arctic, Stohl (2006) emphasized the much larger importance of mid-latitude sources. Resolving such discrepancies is scientifically important but also relevant for creating effective measures to control Arctic pollution levels.

The IPY (International Polar Year) placed a large observational and model focus on the polar regions during the years 2007-2009. During the international POLARCAT GRACE summer campaign in July 2008 a range of data from different 
Table 1. Anthropogenic (AN) and biomass-burning (BB) CO emissions during 1 June-10 July 2008 in the FLEXPART and TOMCAT models. Accounting of biomass-burning $\mathrm{CO}$ emissions is restricted to $15^{\circ} \mathrm{N}$ for both models. FLEXPART anthropogenic emissions exclude South America, Africa and Oceania ( $20 \%$ of the global emissions). AN emissions in the TOMCAT model also include natural emissions from the POET inventory which are not related to fire.

\begin{tabular}{c|cc|cc|cc}
\hline \multirow{2}{*}{$\begin{array}{c}\text { Period } \\
\text { Model }\end{array}$} & \multicolumn{2}{|c|}{ June 2008} & \multicolumn{2}{|c|}{$1-10$ July 2008} & \multicolumn{2}{c}{ Total } \\
& AN & BB & AN & BB & AN & BB \\
\hline FLEXPART & $34.74 \mathrm{Tg}$ & $8.56 \mathrm{Tg}$ & $11.58 \mathrm{Tg}$ & $3.14 \mathrm{Tg}$ & $46.32 \mathrm{Tg}$ & $11.70 \mathrm{Tg}$ \\
TOMCAT & $66.56 \mathrm{Tg}$ & $9.92 \mathrm{Tg}$ & $22.52 \mathrm{Tg}$ & $3.02 \mathrm{Tg}$ & $89.08 \mathrm{Tg}$ & $12.94 \mathrm{Tg}$ \\
\hline
\end{tabular}

platforms were acquired which created an excellent opportunity for an in-depth model-to-data comparison study in the Arctic. During the period 2-10 July 2008 two low-pressure systems moved from Siberia towards the North Pole, one of them even towards Europe, bringing along extensive smoke plumes from biomass burning in Siberia embedded in the associated air masses. The chemical composition of the air masses was measured from aircraft, and observed by active and passive remote sensing instruments from satellite and aircraft platforms.

The aim of this paper is to evaluate to what extent the transport across the pole in terms of the horizontal and vertical structure of air masses is simulated realistically by an Eulerian and a Lagrangian transport model. It is not our aim to decide which model is performing better, but rather to gain a complementary view from the two types of models. Nevertheless we do aim to point out which aspects of the simulations, according to the observations, are reliable and which may be affected by artifacts. In-situ and remote sensing data acquired during the period 2-10 July 2008 are used for reference and validation. In addition, the paper highlights the difficulties in comparing data sets from such distinct sources as models, satellites, and aircraft.

\section{Models and data}

This study is primarily based on the simulation results of two atmospheric transport models: (i) the Lagrangian particle dispersion model FLEXPART (Stohl et al., 2005) and (ii) the Eulerian CTM TOMCAT (Arnold et al., 2005; Chipperfield, 2006). An important distinction between FLEXPART and TOMCAT is that TOMCAT includes a complete set of chemical reactions in the atmosphere, while in FLEXPART only some removal mechanisms are parameterised. We mainly focus on carbon monoxide (CO) in our comparison, as it is typically associated with anthropogenic and biogenic combustion fumes and is hence useful as a tracer for atmospheric pollution transport. Furthermore, $\mathrm{CO}$ is observable by satellite and aircraft, and its atmospheric lifetime in the Arctic during summer is assumed to be sufficiently long
(2-4 weeks) for long-range transport to play an important role.

\subsection{Lagrangian model FLEXPART}

The Lagrangian particle dispersion model FLEXPART was run based on meteorological fields from the ECMWF (European Centre for Medium-Range Weather Forecasts) analyses at $0.5^{\circ} \times 0.5^{\circ}$ resolution. Six-hourly analysis data were supplemented by 3 -h forecast data to increase the time resolution of the meteorological fields. FLEXPART advects hypothetical air parcels of equal mass based on the interpolated threedimensional wind fields and additional random motions that account for turbulence and convection. North of $86^{\circ} \mathrm{N}$, a grid in polar stereographic projection was used to avoid a numerical singularity at the pole. Output data from the FLEXPART calculations were stored at $0.5^{\circ} \times 0.5^{\circ}$ horizontal resolution and on 15 vertical levels.

Emissions from biomass burning were initialized from daily MODIS fire hot-spot data. The fire emissions scaled according to land-use classes were distributed in the lower $150 \mathrm{~m}$ of the atmosphere. Agricultural fires were assumed to have burned during daytime only, while other fires burned for $24 \mathrm{~h}$ (Stohl et al., 2007). Total CO emissions from natural and anthropogenic sources (excluding South America, Africa and Oceania) during June and 1-10 July are listed in Table 1. The model simulation was run with a $\mathrm{CO}$ gas tracer and a black carbon (BC) aerosol tracer. Air parcels of both tracers were removed from the simulation after a life-time of 20 days, assuming that by then the air parcels become incorporated into the so-called atmospheric background (see Sect. 2.5). No chemical production/destruction of $\mathrm{CO}$ was considered, in particular, $\mathrm{CO}$ was not removed by oxidation with the $\mathrm{OH}$ radical. $\mathrm{BC}$ aerosol tracer was removed by wet and dry deposition processes (Stohl et al., 2005). Anthropogenic emissions of $\mathrm{CO}$ and $\mathrm{BC}$ were initialised from the updated EDGAR 3.2 emissions inventory for the year 2000 (Olivier and Berdowski, 2001).

\subsection{Eulerian model TOMCAT}

The TOMCAT model is a three-dimensional Eulerian CTM and has been previously used for a number of atmospheric chemistry transport simulations (Arnold et al., 2005; Chipperfield, 2006). The model is forced using 6-hourly ECMWF operational analyses of wind speed, temperature and humidity. The model was run at a horizontal resolution of $2.8^{\circ} \times 2.8^{\circ}$ with 31 vertical levels up to $10 \mathrm{hPa}$. Largescale advection is implemented using the Prather (1986) scheme. The model accounts for sub-grid scale transport using the Tiedtke (1989) convection scheme and the Holtslag and Boville (1993) parameterization for turbulent mixing in the boundary layer following the method of Wang et al. (1999). The emissions have been updated for the purpose of this study to provide the best available estimate for 2008 . 
Monthly averaged anthropogenic and ship emissions are taken from Streets' v1.2 ARCTAS emission inventory (available from http://www.cgrer.uiowa.edu/arctas/emission.html) with volatile organic compound speciation applied following Lamarque et al. (2010). Isoprene and methanol emissions were calculated using the MEGAN model (Guenther et al., 2006) and all other natural emissions are taken from the POET inventories, as used in the MOZART-4 model, described in Emmons et al. (2010). Note that emissions in July are generally lower than during other months of a year. Nevertheless, emissions used for TOMCAT are higher than the yearly emissions from EDGAR used in the FLEXPART model, as all global emission sources are considered (Table 1). Daily biomass burning emissions estimates of trace gases were compiled specifically for 2008 for the ARCTAS campaign. These were created using MODIS satellite retrievals of hot-spots, area burned estimates and fuel loadings (Wiedinmyer et al., 2006). These daily emission fluxes are regridded to the TOMCAT grid and emitted every timestep and distributed throughout the lowest level gridbox (up to $\sim 113 \mathrm{~m}$ ) (Monks et al., 2011).

The Gaussian grid used in TOMCAT uses a constant longitude space and has a box "edge" at the pole. Consequently, there are a couple of polar transport issues which need to be overcome. For E-W advection the decreasing size of the boxes near the pole means that transport in this direction could violate the Courant-Friedrichs-Levy (CFL) criterion, which specifies that the wind speed for a given timestep and grid size cannot exceed a certain value in order to maintain numerical stability. Typically, the grid box size has to be increased or the timestep decreased to overcome this problem. TOMCAT groups boxes together for the E-W transport to form an "extended polar zone" following the method described in Prather et al. (1987). For the model resolution and timestep used in this study this occurs at gridpoints poleward of $78^{\circ}$ and effectively reduces the model resolution at the pole. For the N-S transport the model uses a full normal grid. However, at the pole there is a singularity (i.e. the box edges have zero size) and the model has an explicit treatment to advect mass from a box to the one diametrically opposite depending on the wind vector at the pole. This allows cross polar transport to be considered in the N-S direction. E-W transport in the last latitude band will also contribute to cross polar transport within the limitation of the model resolution. As the Prather (1986) scheme advects second-order moments (gradient and curvature) of the tracer field along with the mixing ratios, some of the finer-scale structure is retained once a feature has passed over the pole and is distributed over a larger number of gridboxes. Earlier versions of the TOMCAT/SLIMCAT model have been widely used for studies of stratospheric polar ozone and shown very good agreement with observations (Chipperfield et al., 2005).

\subsection{Satellite remote-sensing data}

Total column atmospheric CO observations (TCO) retrieved by the IASI instrument are used to assess the horizontal accuracy of the model simulations. IASI is an infrared sounder on board of the polar-orbiting Metop-A satellite, providing measurements of trace gases such as $\mathrm{CO}, \mathrm{O}_{3}, \mathrm{CH}_{4}, \mathrm{HNO}_{3}, \mathrm{SO}_{2}$ and $\mathrm{H}_{2} \mathrm{O}$ (Clerbaux et al., 2009). It provides near-global coverage twice per day on a $98.7^{\circ}$-inclination sun-synchronous polar orbit at about $817 \mathrm{~km}$ altitude. The local solar time at equator crossing is about 09:30 (ascending node) with a 29-day repeat cycle. Daylight data over land contain more information on the $\mathrm{CO}$ vertical distribution than night data over oceans, because of the impact of thermal contrast (the temperature difference between the ground and the first atmospheric layer) that limits the vertical sensitivity (Turquety et al., 2009). For this study we only used daylight observations, i.e. where the zenith angle was lower or equal to $83^{\circ}$. IASI has a horizontal coverage with a swath of around $2200 \mathrm{~km}$. Each atmospheric view consists of $2 \times 2$ pixels, each with a $12 \mathrm{~km}$ pixel diameter and spaced out $50 \mathrm{~km}$ at nadir. The CO data were retrieved from IASI radiance spectra using the FORLI-CO software developed at the Université Libre de Bruxelles. The employed algorithm is based on the optimal estimation method (Rodgers, 2000) as described in Turquety et al. (2009) and George et al. (2009). CO observations from the IASI instrument have been evaluated in an Arctic environment and were found to provide meaningful results (Pommier et al., 2010).

Since the satellite observations from IASI are not equally sensitive to all atmospheric layers, for a fair comparison the model data had to be weighted with the IASI averaging kernel (AK). This is essentially the same as creating an artificial satellite retrieval from the model data. A mean AK for each day and each $1^{\circ}$ latitude-longitude position has been used, created by averaging the individual AKs from the respective IASI daytime observations (Fig. 1a). Using a local daily mean AK introduces small random errors to the data analysis. To calculate simulated total column retrievals, data from both models have then been weighted using the equation

$y_{\mathrm{o}}=\boldsymbol{A}_{\mathrm{k}} \cdot \boldsymbol{y}_{\mathrm{m}}+\left(\mathbf{I}-\boldsymbol{A}_{\mathrm{k}}\right) \cdot \boldsymbol{y}_{\mathrm{a}}$

where $y_{\mathrm{o}}$ is the simulated satellite retrieval, $\boldsymbol{A}_{\mathrm{k}}$ is the IASI AK vector for a column, $\boldsymbol{y}_{\mathrm{m}}$ is a model data vector, $\mathbf{I}$ is the identity matrix, and $\boldsymbol{y}_{\mathrm{a}}$ is the IASI a priori (Rodgers, 2000; George et al., 2009).

The Cloud-Aerosol Lidar with Orthogonal Polarization (CALIOP) is in orbit on board of the CALIPSO satellite as part of the NASA A-Train suite of satellites (Winker et al., 2009). CALIPSO was launched in 2006, and flies at $705 \mathrm{~km}$ altitude in a $98.2^{\circ}$-inclination sun-synchronous polar orbit. The equator-crossing time is at 10:30 local solar time with a 16-day repeat cycle. CALIOP provides profiles of backscatter at $532 \mathrm{~nm}$ and $1064 \mathrm{~nm}$, as well as the degree of the 

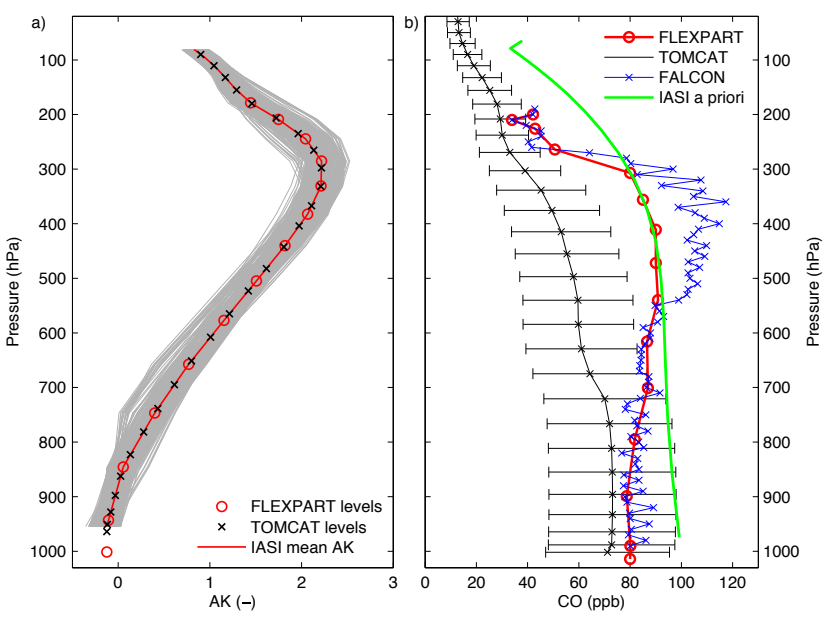

Fig. 1. (a) Background CO profiles from the FALCON GRACE campaign data (blue line), background profile added to the FLEXPART data (red), background CO of the TOMCAT simulations (black), and the a priori for IASI CO retrievals (green). See text for details. (b) Individual averaging kernels (gray) and mean (red) for IASI total column CO retrievals north of $60^{\circ} \mathrm{N}$ (black). FLEXPART and TOMCAT data were weighted with the mean kernel interpolated to the FLEXPART altitude points (red circles).

linear polarization of the $532 \mathrm{~nm}$ signal. Lidar profiles at $532 \mathrm{~nm}$ are available with a vertical resolution of $30 \mathrm{~m}$ (below $8.3 \mathrm{~km})$ and $60 \mathrm{~m}(8.3-20.2 \mathrm{~km})$. We have utilized the level 1B data products (version 3.01) of total attenuated backscatter at $532 \mathrm{~nm}$. The data were ordered and downloaded via ftp from the NASA Langley Atmospheric Science Data Center (see http://eosweb.larc.nasa.gov/).

\subsection{Aircraft measurements}

Measurements from the NASA DC-8 and DLR Falcon 20E aircraft that were deployed in the field during the simultaneous NASA ARCTAS and POLARCAT GRACE campaigns in Canada and Greenland, respectively, were used to provide in situ validation for the model simulations and the construction of a background CO profile. On the DLR Falcon CO was measured with a vacuum UV resonance fluorescence instrument (Gerbig et al., 1999). Data are reported at a $1 \mathrm{~s}$ interval, typically averaging over a flight distance of $\sim 200 \mathrm{~m}$.

On the NASA DC-8 CO was measured by the Differential Absorption CO Measurement (DACOM) instrument. The DACOM spectrometer system is an airborne fast, high precision sensor that includes three tunable diode lasers providing 4.7, 4.5 and $3.3 \mu \mathrm{m}$ radiation for accessing absorption lines of $\mathrm{CO}, \mathrm{N}_{2} \mathrm{O}$, and $\mathrm{CH}_{4}$, respectively (Sachse et al., 1987). For $\mathrm{CO}$, the precision is $2 \%$ or 2 ppbv. The NASA Langley airborne differential absorption lidar (DIAL) system (Browell et al., 1998) makes simultaneous $\mathrm{O}_{3}$ and aerosol backscatter profile measurements with four laser beams: two in the ultraviolet (UV) for $\mathrm{O}_{3}$ and one each in the visible and infrared for aerosols. DIAL makes measurements in both the nadir (below the aircraft) and in the zenith (above the aircraft) which are combined to construct a complete profile. The vertical resolution of DIAL is $300 \mathrm{~m}$ in the nadir and $600 \mathrm{~m}$ in the zenith. Here, only the aerosol backscatter data at $1064 \mathrm{~nm}$ were used. The DC- 8 data at $10 \mathrm{~s}$ time resolution were used, thereby typically averaging over a flight distance of $\sim 2.5 \mathrm{~km}$.

For this study, it is important for a direct comparison of the various data sets that information is extracted at or interpolated to the mutually corresponding points in time and space. To this end, the 1-hourly instantaneous data from TOMCAT were interpolated in space and time and the 3-hourly time and space-averaged data from FLEXPART were sub-sampled to cover the same observational space as probed by the satellite sensor or aircraft. All total column CO data were converted to units of $\mathrm{mg} \mathrm{m}^{-2}$ for comparison.

\subsection{Atmospheric background CO}

Since in this simulation FLEXPART does not retain atmospheric constituents beyond a lifetime of 20 days, a socalled atmospheric background profile had to be added to the FLEXPART data in order to enable quantitative comparisons to the other measurements. Figure $1 \mathrm{~b}$ shows the mean profiles of the minimum $\mathrm{CO}$ mixing ratio at each longitude circle north of $70^{\circ} \mathrm{N}$ from the TOMCAT simulation compared to the mean of the 20th percentile of all CO observations north of $70^{\circ} \mathrm{N}$ from the DLR Falcon made during the POLARCAT GRACE campaign. Interestingly, enhanced background CO mixing ratios of up to $120 \mathrm{ppbv}$ are apparent between 550 $300 \mathrm{hPa}$ in the Falcon measurements (blue line). This uppertropospheric $\mathrm{CO}$ enhancement is most likely a peculiarity of this data set, which is due to the long-range transport of $\mathrm{CO}$ from Canadian and Siberian forest fires at these levels below the tropopause. The global IASI CO a priori profile (Fig. 1b, green line) also suggests that the Falcon background profile is enhanced at these levels.

For the background profile that was added to the FLEXPART data, we followed a smoothed profile of the Falcon CO data below $550 \mathrm{hPa}$ and above $300 \mathrm{hPa}$ (Fig. 1b, red line). In between those levels, we used the IASI a priori as a guidance to constrain the FLEXPART background profile. Essentially, it is not possible to provide a "true" background profile: there is no clear definition when a $\mathrm{CO}$ molecule will be part of the hypothetical well-mixed background reservoir, so any chosen method will be associated with errors. However, since the same background profile is applied throughout this paper, this uncertainty could only cause a constant offset compared to other measurements. Two particular observations in Fig. 1b are noteworthy: (i) the TOMCAT CO background values are throughout the atmospheric column about $10 \mathrm{ppbv}$ lower than the IASI a priori and the FLEXPART background profile, suggesting a bias compared to other data. Note that the background concentrations of the TOMCAT simulations emerge from a free run of the model chemistry based on the 
emission sources. Matching the background values of the observations is thus more challenging for TOMCAT than for FLEXPART where the background is taken from observations. (ii) The IASI a priori retains higher values than all other profiles in the tropopause region $(300-50 \mathrm{hPa})$ and in the lower troposphere $(750-1000 \mathrm{hPa})$, which is due to the use of a global a priori that is probably less realistic at Arctic latitudes.

\section{Results}

\subsection{Meteorology and horizontal plume structure}

\subsubsection{First episode, 2-5 July 2008}

Figure 2 displays the first episode of cross-Arctic pollution transport during 2-5 July 2008 as total-column CO simulated by the FLEXPART model (left column) and TOMCAT (right column). The dynamical tropopause, indicated by the 2 pvu contour at $320 \mathrm{~K}$ (blue line, left column) clearly separates more CO-rich mid-latitude air-masses from the relatively clean Arctic atmosphere ( $\left.\sim 600-700 \mathrm{mg} \mathrm{m}^{-2} \mathrm{TCO}\right)$. The white contours in the right column depict sea level pressure (SLP). SLP and the tropopause are both taken from the ECMWF analysis data.

At 2 July 2008 06:00 UTC a large part of eastern Siberia in the FLEXPART and TOMCAT simulation is covered by very high TCO values $\left(>1600 \mathrm{mg} \mathrm{m}^{-2}\right.$, Fig. $\left.2 \mathrm{a}, \mathrm{b}\right)$. The high TCO values are caused by extensive forest fires in eastern Siberia that had been burning since end of June 2008. Ahead of a stratospheric streamer near $160^{\circ} \mathrm{E}$ pollution-rich mid-latitude air is advected to higher latitudes in a narrow plume. The SLP field shows that a weak low-pressure system is located under the stratospheric streamer near $150^{\circ} \mathrm{E} / 70^{\circ} \mathrm{N}$ (Fig. 2b, white contours). This weak baroclinic system is also apparent in IR imagery (O. Cooper, personal communication, 2010). The CO-rich plume is mostly confined by the tropopause boundary (Fig. 2a, blue contour). In general, the TCO fields from both models agree in the overall structure. In the TOMCAT simulation gradients are mostly smoother as can be expected from the coarse-grid simulation. The high$\mathrm{CO}$ tongue extending towards the pole has markedly lower concentrations in TOMCAT.

At 3 July 2008 00:00 UTC the tropospheric streamer has progressed further north, thereby elongating meridionally and approaching disconnection from the mid-latitude reservoir (Fig. 2c, d). The low-pressure signature in the SLP field has weakened and is now located at $140^{\circ} \mathrm{E} / 80^{\circ} \mathrm{N}$. In the TOMCAT simulation, gradients are further smoothened while the plume is advected towards the pole. Maximum TCO values of the plume are still $>1600 \mathrm{mg} \mathrm{m}^{-2}$ in the FLEXPART simulation, while in TOMCAT maximum values are $\sim 950 \mathrm{mg} \mathrm{m}^{-2}$, despite larger TOMCAT emissions (Table 1). At 4 July 2008 00:00 UTC (Fig. 2e, f), the mid- latitude plume has begun to curl up anticyclonically directly over the North Pole. Eroding along its boundaries, it is being incorporated into the surrounding atmosphere. The lowpressure system has become stagnant near $120^{\circ} \mathrm{E} / 75^{\circ} \mathrm{N}$. In the FLEXPART simulation the plume is shedding fine filaments, indicating the Lagrangian representation of plume dispersion. The Eulerian TOMCAT model has transformed the mid-latitude plume into a broad area of weakly enriched pollution. The difference between the TCO maxima in the FLEXPART simulation and TOMCAT near the pole has further increased ( $>1600 \mathrm{ppbv}$ in FLEXPART vs. $\sim 850 \mathrm{ppbv}$ in TOMCAT).

As mid-latitude air is simultaneously moving poleward at 5 July 2008 12:00 UTC over eastern Siberia and the Nordic Seas (Fig. 2g, h) the remaining mid-latitude plume over the North Pole is strongly sheared apart and moves as fine filaments into the Canadian Arctic and across Svalbard $\left(16^{\circ} \mathrm{E}\right.$, $78^{\circ} \mathrm{N}$ ) towards Scandinavia in the FLEXPART simulation (Fig. 2g). In the TOMCAT simulation only weak indications of such fine-scale structures remain which are too small to be resolved at the model's grid resolution. The locations of these weak structures agree however with the much more pronounced filaments in the FLEXPART model. Other parts of the plume have by now mostly become incorporated into the Arctic background CO.

Figure 3 shows a vertical cross-section through the pollution plume along $160^{\circ} \mathrm{E} / 20^{\circ} \mathrm{W}$ across the pole as indicated in Fig. 2e, f. In the FLEXPART simulation (Fig. 3a) the midlatitude plume is shown as a marked feature with high $\mathrm{CO}$ mixing ratios ( $>200 \mathrm{ppbv}$ ) over the pole directly below the tropopause. Isentropically, the air mass still carries a signature of its origin near $40-50^{\circ} \mathrm{N}$ with potential temperatures of $\sim 320 \mathrm{~K}$. In the TOMCAT simulation (Fig. 3b) the feature is more confined in the vertical and has lower mixing ratios (140-160 ppbv). Since CO mixing ratios are equally high in the area of the forest fire emissions near $50^{\circ} \mathrm{N}$, the difference between the two simulations is probably related to the different diffusion properties in the Lagrangian and the Eulerian model.

In addition, chemical loss and production processes in TOMCAT may also create some of the difference. In particular oxidation with the hydroxyl radical $(\mathrm{OH})$ is an important, seasonally varying sink of $\mathrm{CO}$ in the atmosphere. During polar summer, model estimates of $\mathrm{OH}$ concentrations are about 10 times higher than during polar night (10$15 \times 10^{5}$ molecules $\mathrm{cm}^{-3}$ vs. $<1 \times 10^{5}$ molecules $\mathrm{cm}^{-3}$, Bey et al. (2001)). Simulated $\mathrm{OH}$ concentrations in CTMs are however uncertain (Shindell et al., 2008). Typical global atmospheric lifetimes of $\mathrm{CO}$ against oxidation by $\mathrm{OH}$ are estimated to about 2 months (Fisher et al., 2010). For Arctic summer conditions we assume shorter lifetimes, on the order of 2-4 weeks. It may be possible that the enhanced numerical diffusion of $\mathrm{CO}$ in the coarse-grid model also increases the effectiveness of the reaction with $\mathrm{OH}$, which then would further contribute to lower $\mathrm{CO}$ concentrations. Unlike the 

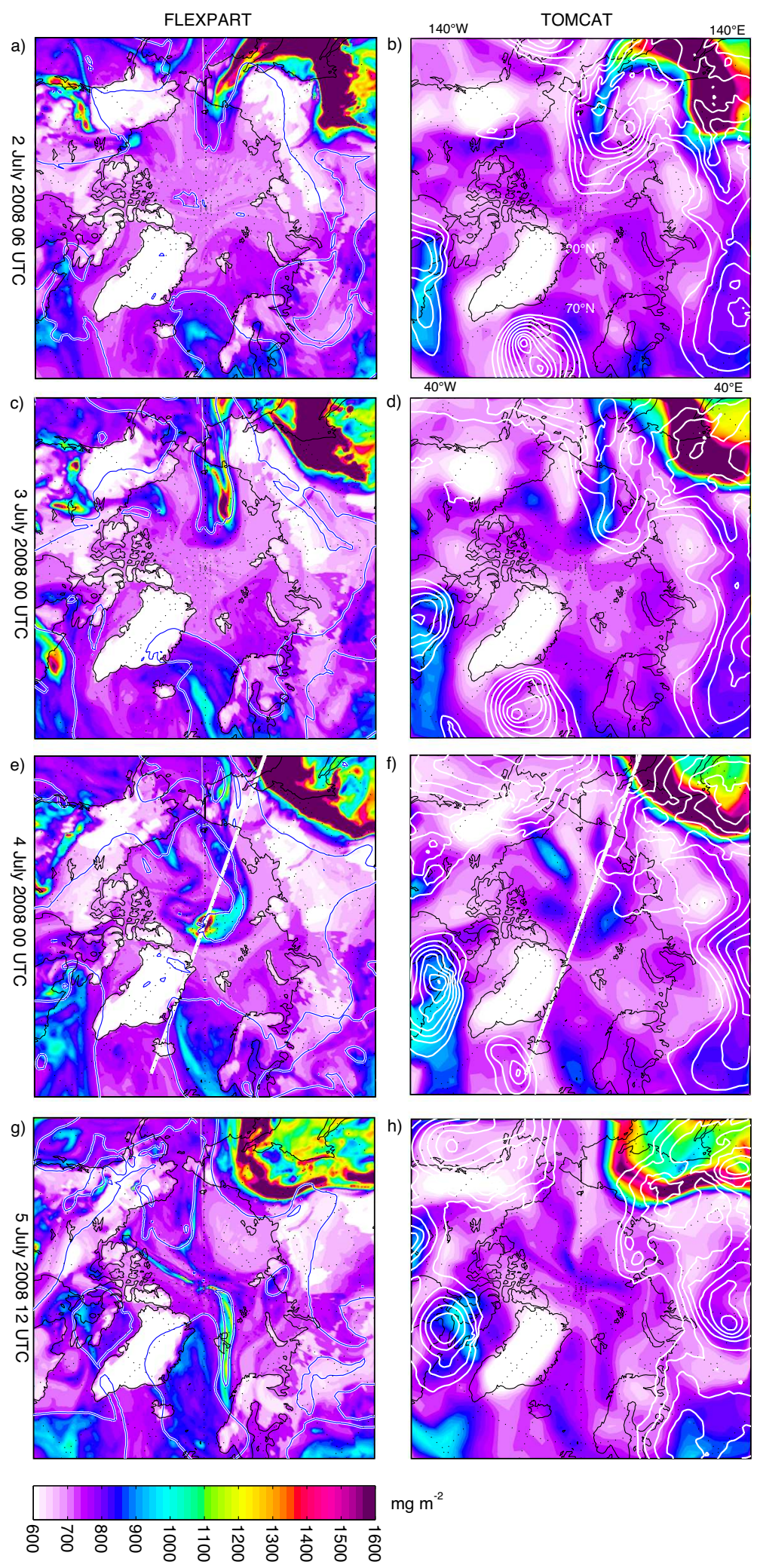

$\mathrm{mg} \mathrm{m}^{-2}$

Fig. 2. Total column CO (shading, $\mathrm{mg} \mathrm{m}^{-2}$ ) during the period 2 July 2008 06:00 UTC to 5 July 2008 12:00 UTC in the FLEXPART model simulation (left column) and the TOMCAT model simulation (right column). The meteorological situation is denoted by the dynamic tropopause in the left column ( 2 pvu isoline at the $320 \mathrm{~K}$ isentrope, blue line) and sea-level pressure in the right column (white contours, 1010 to $970 \mathrm{hPa}$ at $3 \mathrm{hPa}$ interval) using ECMWF analysis data. Thick white line denotes the transect shown in Fig. 3. 


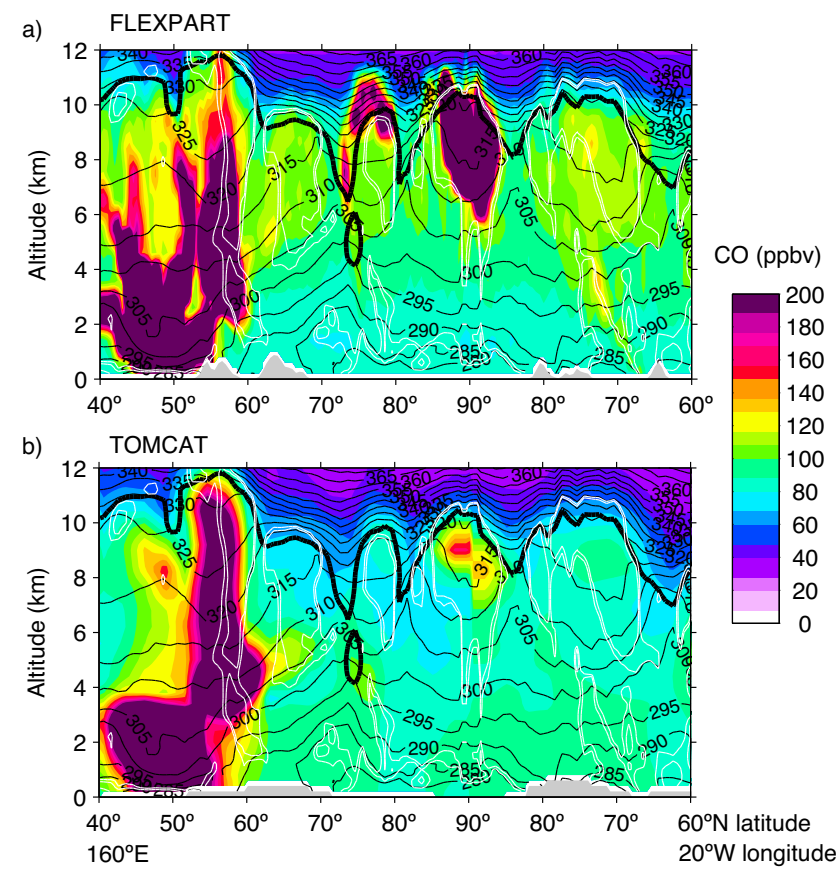

Fig. 3. Vertical cross-sections of $\mathrm{CO}$ concentrations in ppbv through the Arctic atmosphere on 4 July 2008 00:00 UTC from $60^{\circ} \mathrm{N}$ to $40^{\circ} \mathrm{N}$ along $160^{\circ} \mathrm{E} / 20^{\circ} \mathrm{W}$ through (a) the FLEXPART simulation and (b) the TOMCAT simulation. Meteorological conditions are shown by contours of potential temperature (thin black lines), relative humidity (80 and 90 percent, white solid lines), and the dynamical tropopause ( 2 pvu, thick black line) from ECMWF analysis data.

TOMCAT model, the removal of $\mathrm{CO}$ by the reaction with $\mathrm{OH}$ is not represented in the FLEXPART model simulation. The combination of a fixed 20-day lifetime with the background $\mathrm{CO}$ profile is intended to take this missing process to some extent into account implicitly.

\subsubsection{Second episode, 6-10 July 2008}

At the beginning of the second episode on 6 July 2008 06:00 UTC the large CO-rich plume over eastern Siberia intrudes into the Arctic atmosphere, again ahead of a stratospheric streamer (Fig. 4a). At the surface a low-pressure system is forming near $160^{\circ} \mathrm{E} / 70^{\circ} \mathrm{N}$ (Fig. $4 \mathrm{~b}$ ). While the overall size and shape of the plume agree very well between the two simulations, differences in the location and extent of the TCO maxima can be noted that are probably related to different forest fire emission schemes and emission inventories (see Table 1).

On 7 July 2008 00:00 UTC (Fig. 4c, d), the polluted airmass advances further towards the pole and the low-pressure system rapidly intensifies near the western tip of the advancing mid-latitude airmass $\left(170^{\circ} \mathrm{E} / 78^{\circ} \mathrm{N}\right)$. The large plume elongates and reaches northern Greenland on 8 July 2008 12:00 UTC (Fig. 4e, f). The low-pressure system has fur- ther deepened, reaching a minimum pressure of $<986 \mathrm{hPa}$. The plume has acquired undulations along its outer boundary which are closely matched by the tropospheric wave guide (Fig. 4e, blue contour). The plume structure is quite similar in both models, but more diffusion of $\mathrm{CO}$ into the surrounding air masses is apparent in the TOMCAT simulation. This agrees with the finding of Rastigejev et al. (2010) that a more complex plume boundary leads to its more rapid diffusive disintegration in Eulerian model simulations.

As on 10 July 2008 06:00 UTC the low-pressure system reaches Svalbard, it has heavily deformed the pollution plume, leading to its disintegration into separated maxima (Fig. 4h). Interestingly, the core of the low-pressure system itself appears to remain mostly free from mid-latitude pollution. As the plume is split into smaller segments, the stronger diffusion in the Eulerian simulation rapidly smoothes the horizontal TCO structures. Evidently, the width of the plume in relation to the grid resolution influences how prone it is to numerical diffusion.

A vertical cross-section on 8 July 2008 12:00 UTC (Fig. 5) along $170^{\circ} \mathrm{W} / 10^{\circ} \mathrm{E}$ as indicated in Fig. 4e, f shows the progression of the polluted air mass towards the pole. The warm mid-latitude air masses have lifted the polar tropopause substantially. As indicated by the white contours, the air mass is humid and mostly embedded in clouds. At about $78^{\circ} \mathrm{N}$ the plume slides on top of the cold polar dome. Its lower boundary reaches to 5-6 km near the North Pole. The CO mixing ratios in FLEXPART are in general higher than in the TOMCAT simulation (Fig. 5a). This is particularly evident close to the mid-latitude source regions, which would point to differences in the emissions, but in fact TOMCAT emissions are slightly higher than FLEXPART for biomass burning (Table 1). Hence, most likely, differences can be attributed to the reaction of $\mathrm{CO}$ with $\mathrm{OH}$ which is not represented in the FLEXPART model. The diabatic transport processes that were involved in lifting this air mass near the polar tropopause are investigated in detail in a study based on aircraft data from the same campaign (Roiger et al., 2011).

\subsubsection{Advection across the pole}

The direct advection of the pollution plumes across the North Pole allows us to investigate effects of the numerical advection scheme on the plume structure. Figure 6 shows a time sequence of the TCO field during 7 to 9 July 2008 as the pollution is crossing the pole. All data are shown directly on the output grid for clarity. While the TOMCAT model has to deal with the convergence of the meridians towards higher latitudes and a singularity at the pole, the Lagrangian FLEXPART model is per design not prone to resolution issues, and in addition switches to a stereographic projection for calculating advection in the vicinity of the pole.

On 7 July 2008 00:00 UTC, a small plume is shed east of the main plume that disperses quickly over the Russian Arctic (Fig. 6a, d, arrow). From the tropopause contour there 

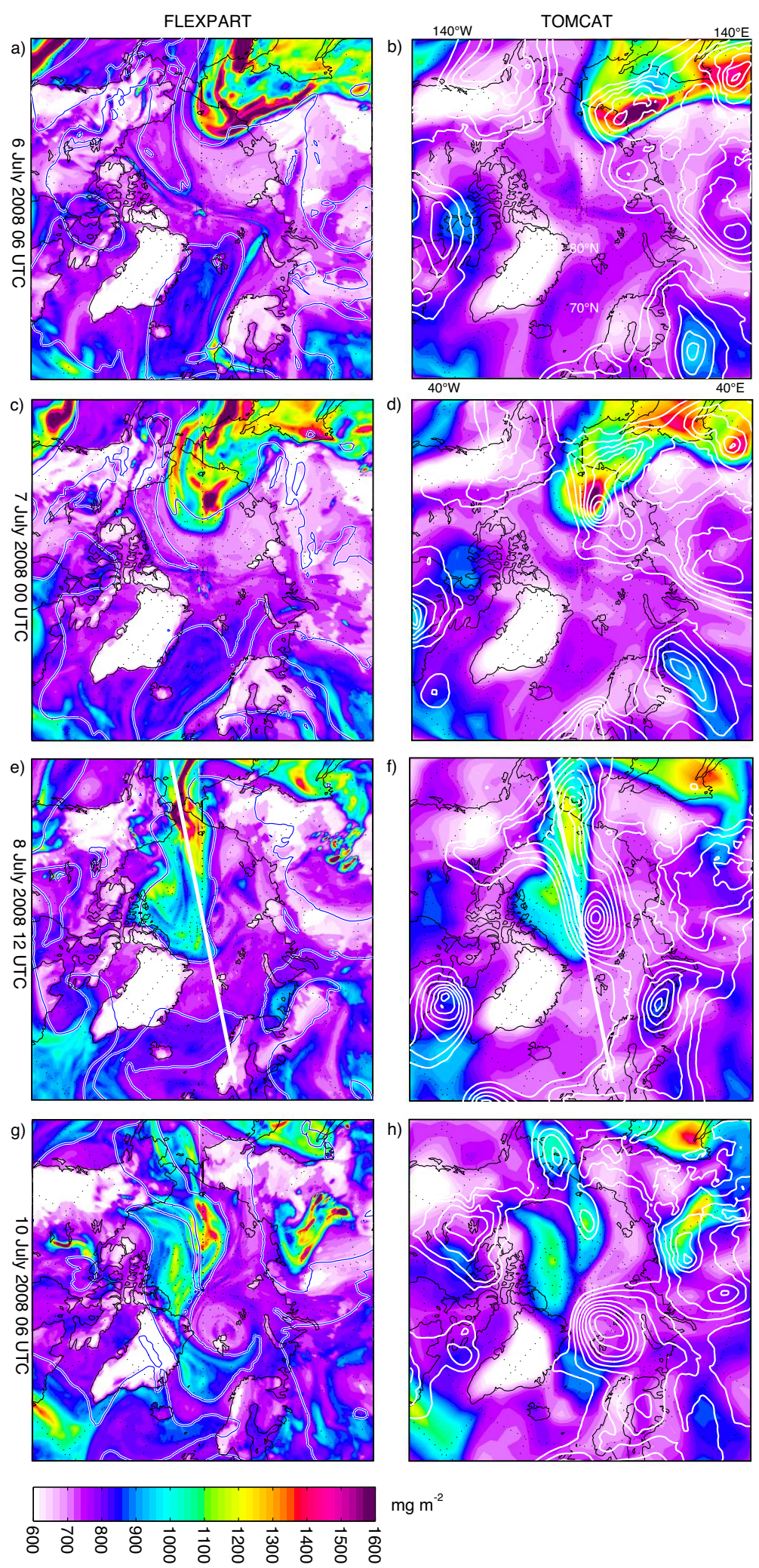

Fig. 4. As Fig. 2, but for the period 6 July 2008 06:00 UTC to 10 July 2008 06:00 UTC. Thick white line denotes the transect shown in Fig. 5. 


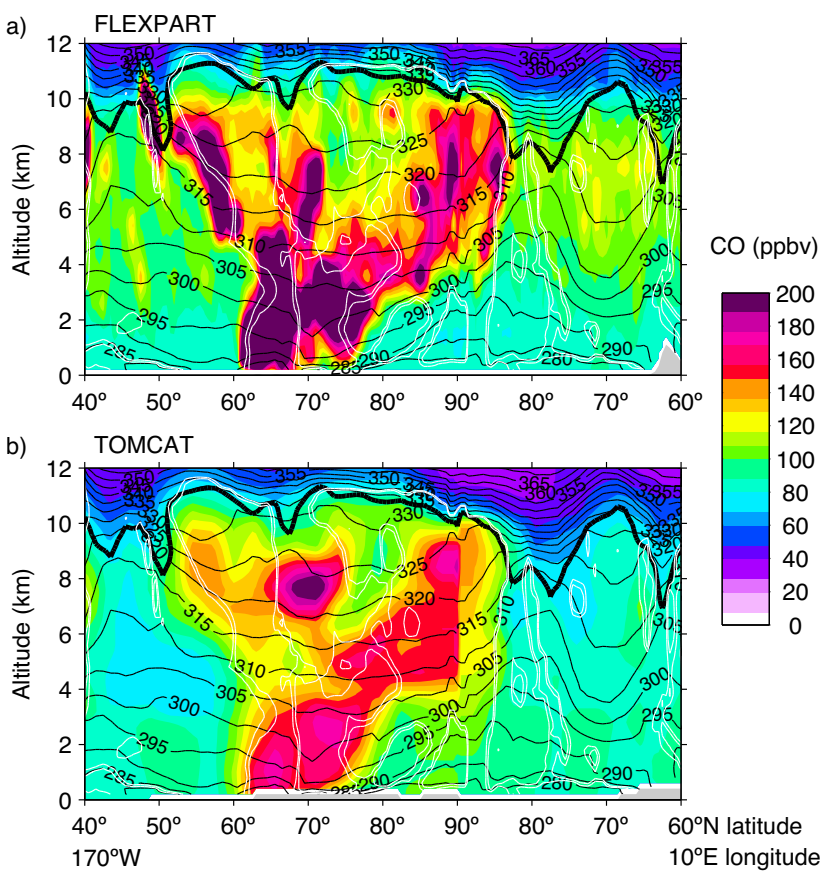

Fig. 5. As Fig. 3, but for a vertical cross-sections through the Arctic atmosphere on 8 July $200812: 00 \mathrm{UTC}$ from $60^{\circ} \mathrm{N}$ to $40^{\circ} \mathrm{N}$ along $170^{\circ} \mathrm{W} / 10^{\circ} \mathrm{E}$.

is no indication of a large-scale dynamic cause for this rapid spread. $12 \mathrm{~h}$ later, in the TOMCAT simulation another partial plume is circumnavigating the pole on the eastern side, associated with enhanced diffusion. This second feature is not visible in the FLEXPART simulation (Fig. 6b, e). Apparently, the minor plume is produced by the box grouping of the Prather et al. (1987) advection scheme in TOMCAT described earlier (Sect. 2.2). This results in a spreading of the tracer mass across a larger volume, and reduced CO mixing ratios. As the plume progresses further on 9 July 2008 00:00 UTC (Fig. 6c, f), the plume shape has regained some of the structure present before crossing the pole, effectively showing the result of the unpacking of second order moments from the Prather scheme. Given the difficulties of simulating a finely structured plume crossing the pole, and the relatively coarse grid resolution, the TOMCAT plume looks remarkably similar to the FLEXPART simulation results at the end of the displayed time sequence.

To investigate the effect of horizontal grid resolution on the shape of the pollution plume, an additional model simulation was conducted using the higher-resolution Eulerian model WRF-Chem (Weather Research and Forecasting model coupled with Chemistry, Grell et al. (2005)). Results from this simulation are not presented in detail here, see Sodemann et al. (2010) for a more extended discussion. The model was run for the period 25 June 2008 00:00 UTC 10 July 2008 18:00 UTC using 6-hourly $0.5^{\circ} \times 0.5^{\circ}$ ECMWF analysis as input data. The model domain covered the area north of $20^{\circ} \mathrm{N}$ at a horizontal grid resolution of $50 \mathrm{~km}$, with 34 vertical levels up to $20 \mathrm{hPa}$. WRF-Chem simulates the shape of the pollution plume during passage over the North Pole as an intermediary between the FLEXPART and TOMCAT simulations. Numerical diffusion was clearly leading to smoother gradients than the Lagrangian FLEXPART simulation, albeit some more fine-scale structure could be retained than in the coarse-grid Eulerian TOMCAT simulation (see Sodemann et al. (2010), Fig. 6).

\subsection{Comparison with satellite observations}

The comparison between the two transport models FLEXPART and TOMCAT has shown that the structures of the CO-rich air masses are overall similar in shape, in particular for larger features. Smaller features and finer-scale structures however are represented quite differently in their concentration gradients. Satellite remote-sensing data are employed now to compare both model simulations in terms of spatial structure and magnitude of TCO to a reference data set.

Figure 7 shows daily composites of all daylight retrievals of the satellite observations and the model fields sampled at the same space/time locations during 3-8 July 2008. Due to the daily compositing, the structures in Fig. 7 do not find their direct correspondence in the time snapshots of TCO displayed in Figs. 2 and 4. The gray area in the IASI observations (Fig. 7, center column) are missing data due to impenetrable cloud cover. Most thick clouds are in mid-latitudes and over forest fires as in Canada, while the view into the Arctic atmosphere is mostly cloud-free. The low values over Greenland in all panels are due to the reduced atmospheric column over orography (Pommier et al., 2010). Both models were weighted with local daily mean IASI averaging kernels (see Sect. 2).

On 3 July 2008 (Fig. 7a-c), both models and the satellite image show the first, smaller plume between eastern Siberia and the North Pole as a hook-like structure. The TCO maximum over south-eastern Siberia, over Scandinavia and south of Greenland are other areas with good model/satellite correspondence. Agreement is less good over western North America and Alaska. Maximum values in the IASI data are beyond the color scale $\left(>1700 \mathrm{mg} \mathrm{m}^{-2}\right.$ ). Visually, the IASI TCO observations appear more similar to the FLEXPART model than to TOMCAT. On average, the median of the difference between IASI and FLEXPART TCO is $53 \mathrm{mg} \mathrm{m}^{-2}$, while the TOMCAT TCO is $188 \mathrm{mg} \mathrm{m}^{-2}$ lower than IASI (note the different color scale in Fig. 7, right column). Throughout the simulation, $\mathrm{CO}$ concentrations are increasing in the FLEXPART simulation which leads to larger biases compared to IASI in the beginning (median $102.4 \mathrm{mg} \mathrm{m}^{-2}$ on 2 July 2008$)$ than in the end $\left(0.5 \mathrm{mg} \mathrm{m}^{-2}\right.$ on 10 July 2008$)$.

On 4 July 2008 (Fig. 7d-f), IASI shows the curled-up plume with two clear TCO maxima near the pole. While the Lagrangian FLEXPART model represents the structure of the maxima well, it is beyond the resolution of the Eulerian 

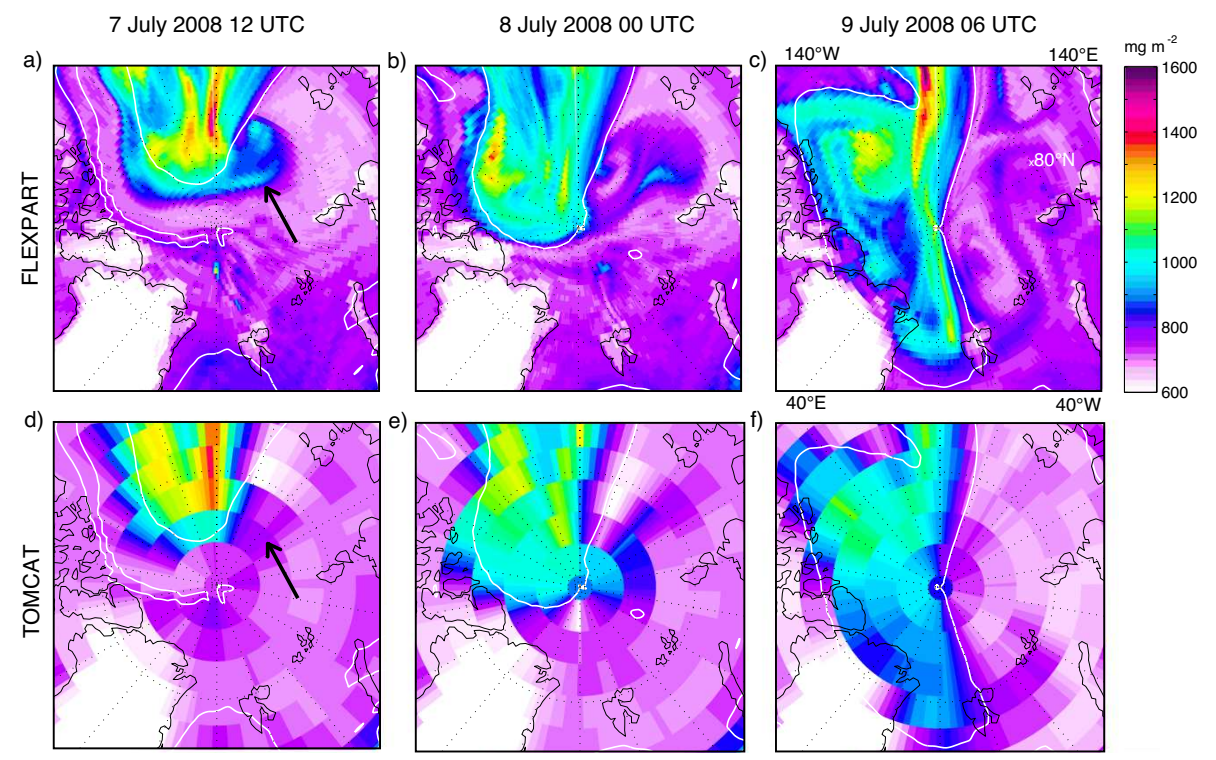

Fig. 6. Zoomed view of total column CO (shading, $\mathrm{mg} \mathrm{m}^{-2}$ ). (a-c) Total column CO from the FLEXPART simulation on 7 July 2008 12:00 UTC, 8 July 2008 00:00 UTC and 9 July 2008 06:00 UTC. (d-f) Total column CO from the TOMCAT simulation for the same period. White contour shows the dynamical tropopause at $320 \mathrm{~K}$ (2 pvu). Data are shown on the output grid without spatial interpolation.

TOMCAT model to realistically represent concentrations during this break-up. This is more obvious one day later on 5 July 2008 (Fig. 7g-i), where IASI and FLEXPART, but not TOMCAT, show a narrow, elongated feature reaching from the pole towards Scandinavia. The filament was $\sim 220$ $300 \mathrm{~km}$ wide, at an elongation of $\sim 2500 \mathrm{~km}$, both in the IASI data and the FLEXPART simulation. Another filament extending towards the Canadian Arctic in the FLEXPART simulation was only $\sim 100 \mathrm{~km}$ wide, but appears broader in the satellite observation. The finding that such a narrow filament both in extension and location is very closely simulated by FLEXPART is an impressive demonstration of the capabilities of a Lagrangian model.

As the large pollution plume is advancing towards the pole on 6 and 7 July 2008 (Fig. 7j-l and m-o), both models agree well with the IASI observation. At that time, the plume is between $850 \mathrm{~km}$ and $1600 \mathrm{~km}$ wide, indicating the scale of pollution features which is also well represented in the TOMCAT model. The larger size of the polluted airmass leads to a smaller influence of numerical diffusion, and better correspondence between models and satellite retrievals. The TCO maxima in the large plume agree well between the models on 7 July 2008, also as it is reaching northern Greenland on 8 July 2008 (Fig. 7p-r). TCO concentrations at the eastern flank of the plume are lower, possibly due to differences in the biomass burning emission scheme.

In general, it is remarkable how well the structure of the pollution plumes agree between the satellite observations and both model simulations. This underlines that (i) the plumes simulated by the models have very similar correspondence in the real world as seen by the IASI satellite, and (ii) the
ECMWF analysis data that are used for driving both model simulations are very reliable, even at high latitudes where weather observations at the surface are generally sparse.

The better agreement between the IASI observations and the FLEXPART simulation in particular for fine-scale structures leads to the conclusion that the sharp gradients and narrow features predicted by the Lagrangian model (Sect. 3.1) are indeed a real feature of atmospheric transport at these high latitudes. Not surprisingly, the Eulerian model has too much numerical diffusion at the grid-resolution applied here, which leads to an unrealistic smoothing of the TCO gradients, and the disappearance of fine-scale features.

It is interesting to compare the TCO fields from the model simulations and the IASI satellite quantitatively. Figure 8a, b show the probability density distributions of a correlation between all IASI observations and the FLEXPART and TOMCAT model simulation, each transformed with the respective IASI AK. FLEXPART deviates from the IASI observations, with the exception of values at $\sim 800 \mathrm{mg} \mathrm{m}^{-2} \mathrm{TCO}$, which is the level of background concentrations. FLEXPART data below $\sim 650 \mathrm{mg} \mathrm{m}^{-2}$ TCO are typically lower due to the underlying orography, with increasing concentrations scatter also increases. For values above $\sim 1500 \mathrm{mg} \mathrm{m}^{-2} \mathrm{TCO}$, part of the AK-weighted FLEXPART data show a high bias. The comparison between IASI and the TOMCAT data (Fig. 8b) shows a clear low bias that becomes stronger for values above $\sim 800 \mathrm{mg} \mathrm{m}^{-2} \mathrm{TCO}$. The reason for the lower TCO values in TOMCAT compared to Figs. 2, 4 is that applying the IASI averaging kernels emphasizes the upper-tropospheric part of the atmospheric column (Fig. 1a), where TOMCAT has the strongest low bias (Fig. 1b). Additionally, there is a cloud 

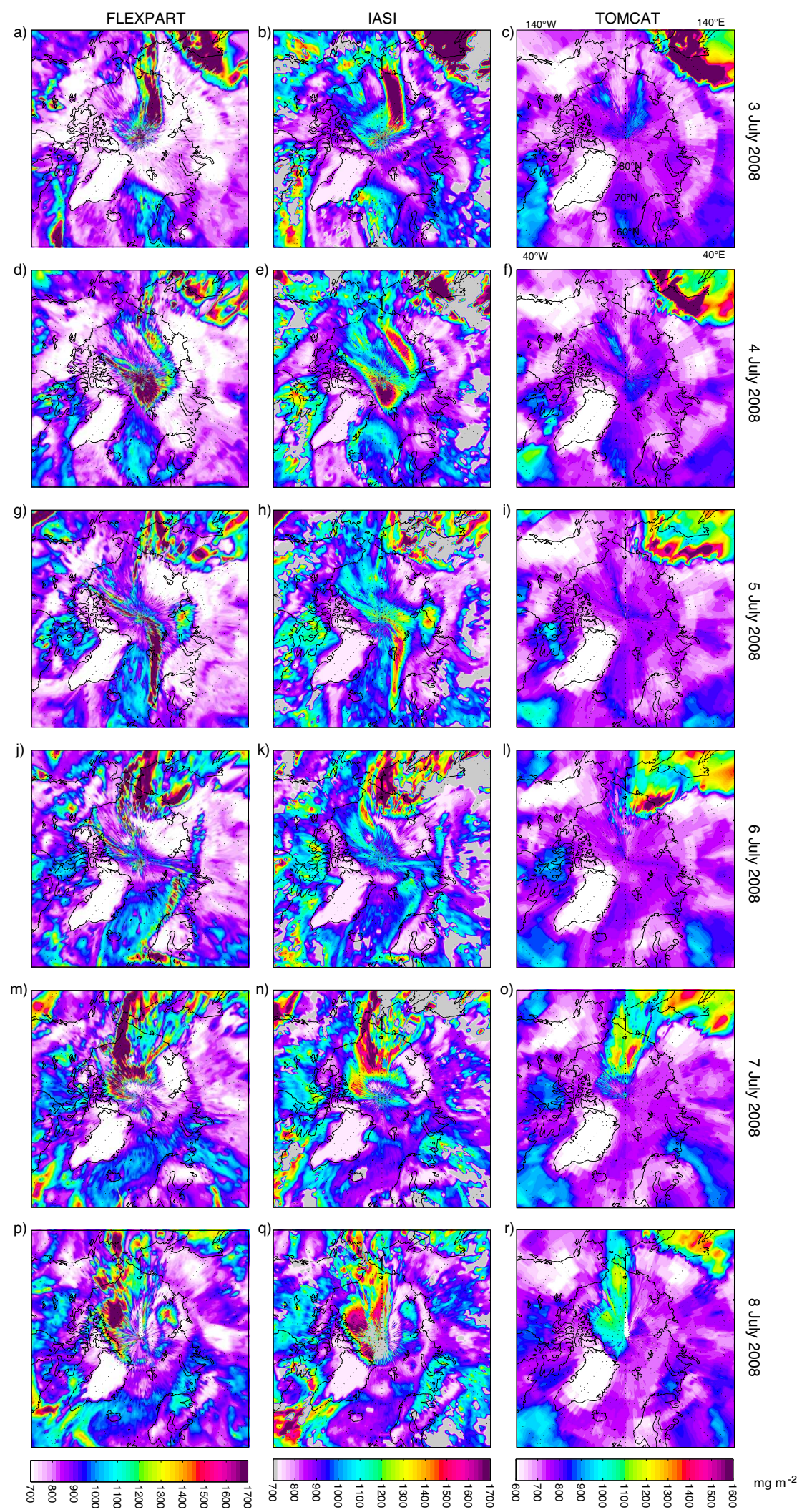

Fig. 7. Comparison of total column CO from FLEXPART (left column), IASI (center column) and TOMCAT (right column) in $\mathrm{mg} \mathrm{m}^{-2}$ during 3 to 8 July 2008. Displayed are IASI daylight composites. Model data are interpolated to the same time and location as the satellite retrievals and weighted with a mean IASI averaging kernel. Cloudy pixels in the IASI data are shown in white as missing data. 

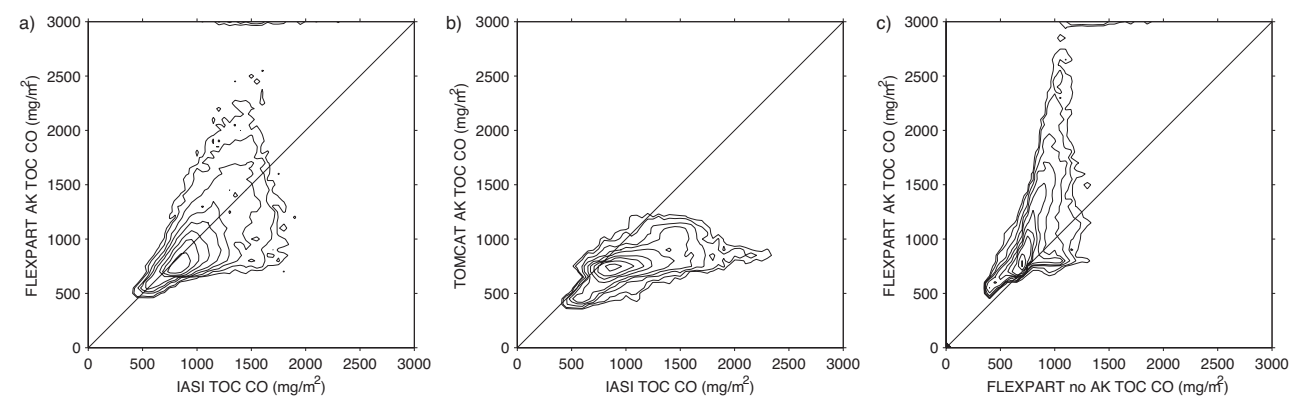

Fig. 8. (a) Probability density distribution of AK weighted FLEXPART simulation vs. IASI retrievals, (b) AK weighted TOMCAT simulation vs. IASI retrievals, (c) AK weighted FLEXPART simulation vs. FLEXPART simulation without AK weighting. Contour intervals are $(1,2,5) \times 10^{-4},(1,2,5) \times 10^{-3},(1,2,5) \times 10^{-2}, 1 \times 10^{-1}$.

of data points of IASI TCO above $2000 \mathrm{mg} \mathrm{m}^{-2}$ that corresponds to data points of TOMCAT TCO of only about $700 \mathrm{mg} \mathrm{m}^{-2}$. These data points are mostly located in the first, narrow $\mathrm{CO}$ plume that is removed too quickly by numerical diffusion in the TOMCAT model. Further possible causes of low biases of the model simulations are further investigated in Sect. 4.

In this context it is insightful to investigate how the actual model TCO values compare with the simulated retrieval values. Figure $8 \mathrm{c}$ compares the TCO data points from the FLEXPART simulation without application of an AK vs. such weighted with the mean IASI AK (Eq. 1). The simulated retrievals are much higher than the model data without kernel weighting. The overestimation increases steeply, despite some scatter, with increasing CO concentrations for values larger than $\sim 800 \mathrm{mg} \mathrm{m}^{-2}$ TCO. Effectively, the simulated retrieval has more pronounced maxima than the model atmosphere actually contains. This can be seen by comparing e.g. Figs. 2a and 7a. One possibility is that the background added to FLEXPART may be too high in the upper troposphere, while the prior is higher in the lower troposphere than the mean of the observations (Fig. 1b). In combination, the application of an AK then stretches the range of values to excessively high values compared to the simulated state of the atmosphere. This kind of diagnostic could be useful to test the influence of an a priori that varies with latitude and season on simulated retrievals. One implication may be that the IASI data used here overestimate the pollution of the upper troposphere, and actually represent an atmosphere closer to the state represented in the FLEXPART model.

\subsection{Comparison between models and CALIPSO data}

The vertical distribution in the atmosphere is an important factor determining the lifetime and transport of $\mathrm{CO}$ released from forest fires. The vertical location of $\mathrm{CO}$ in the model simulations is first determined by the emission schemes employed by the models. During atmospheric transport, lifting approximately along isentropes or fronts and mixing take place. While the horizontal structure of pollution plumes can

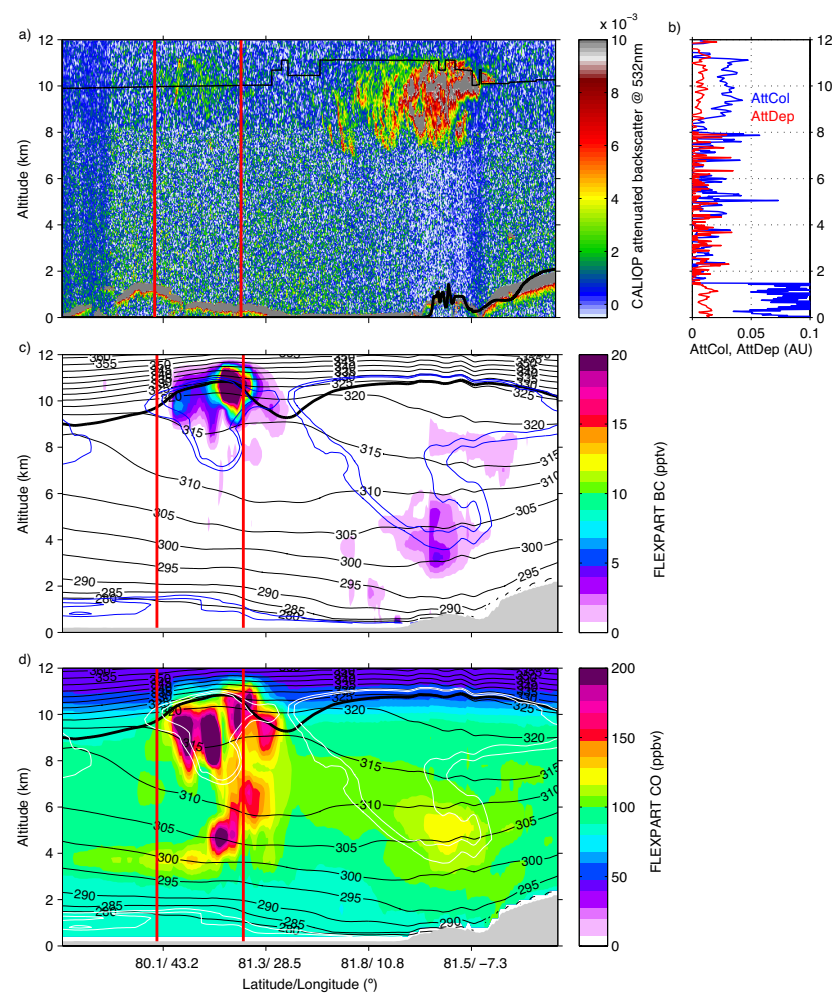

Fig. 9. Comparison of simulation data with the space-borne CALIPSO lidar for an aerosol feature observed on 5 July 2008 07:00 UTC near Greenland (see Fig. 2d). (a) Aerosol backscatter and depolarization from the CALIPSO satellite and vertical mean for the feature delineated by red vertical lines, (b) Mean profiles of attenuated color ratio (blue, AttCol) and attenuated depolarization (red, AttDep) in arbitrary units averaged over the segment marked by red lines in panel (a), (c) FLEXPART black carbon tracer concentration (pptv), (d) CO concentration (ppbv) from FLEXPART. Meteorological conditions are indicated by the dynamical tropopause ( $2 \mathrm{pvu}$, thick black and white contour), potential temperature (thin black contours), and relative humidity ( $80 \%$ and $90 \%$, blue and white contours) from ECMWF analyses. Red lines indicate the location of the aerosol feature. 
be readily measured from satellite platforms, it is considerably more challenging to validate the vertical structure of the transport model simulations. Here we use the aerosol measurements from the space-born lidar instrument CALIOP as a proxy for pollution transport in the models. As we do not simulate aerosols in the TOMCAT model this comparison is carried out using the FLEXPART model only.

Out of 10 opportunities during the study period where aerosol was clearly detected in the CALIPSO profiles two cases have been selected where aerosol was at high and medium-low altitudes, respectively. A first case has been identified where aerosol is visible in the highly lifted and filamented plume that is exiting the Arctic on 5 July 2008 07:09 UTC near $20^{\circ} \mathrm{E} / 81^{\circ} \mathrm{N}$ (compare Fig. $2 \mathrm{~g}$, h). An area of enhanced color ratio and with low attenuated depolarization is visible at altitudes of $10-12 \mathrm{~km}$ in the section of the curtain contained by the red markers (Fig. 9b). The much stronger backscatter signal further to the right in Fig. 9a indicates an ice cloud.

The discrimination between clouds and aerosols in CALIOP observations is performed based on the differences in their optical and physical properties. It is based on an automated cloud and aerosol discrimination (CAD) algorithm (Liu et al., 2009). The CAD algorithm is a multidimensional, at present latitude-independent, probability density function (PDF) based approach (Liu et al., 2004). Attributes used are lidar backscatter intensity, wavelength dependency, depolarization ratio, layer heights or ancillary parameters (e.g., temperature, pressure, location, season). The algorithm is most representative of the cloud and aerosol distributions at lower latitudes. Therefore, some misclassifications of optically thin polar clouds (or edges of such clouds) can occasionally occur.

Low depolarization indicates spherical particles and a constant color ratio confirms a uniform particle size is seen in the volume over the section of the curtain contained by red markers (Fig. 9b). Nevertheless, this feature is classified as cloud, partly with low or no confidence, and as stratospheric feature, by the CALIPSO CAD (not shown).

The cross-section through the black carbon tracer field of the FLEXPART model (Fig. 9a) shows a maximum at the same altitude but slightly displaced horizontally. The ECMWF tropopause (thick black contour) is somewhat elevated at this location, probably due to diabatic effects as indicated by the high relative humidity (blue contours). Note that the BC tracer apparently has partly been lifted into the stratosphere. The FLEXPART CO tracer shows that the aerosol in the tropopause region is a remainder of a deeper and more extensive pollution feature (Fig. 9c). Several subsequent CALIPSO crossings at later times confirm the observation of this elevated aerosol plume (not shown). The good colocation of these observations with the FLEXPART black carbon tracer, strengthens the indication that the CALIOP feature is indeed aerosol, wrongly classified as cloud structure.
A second case is a crossing of the CALIPSO satellite over a large active forest fire in Siberia near $110^{\circ} \mathrm{E}, 60^{\circ} \mathrm{N}$ on 8 July 2008 19:22 UTC (Fig. 4e, f). The CALIPSO curtain shows the aerosol load as high attenuated backscatter with a maximum at $\sim 3 \mathrm{~km}$ altitude, and extending to above $5 \mathrm{~km}$ in the vertical (Fig. 10b).

The mean profiles of attenuated depolarization and color ratio confirm the presence of aerosol more clearly than in the previous case. The CALIPSO vertical feature mask identifies the region clearly as aerosol (not shown). In the FLEXPART BC tracer field, a strong aerosol signal can be seen that corresponds well with the horizontal location of the feature in the CALIPSO data. The feature however has a distinctively lower vertical extent in the simulation (Fig. 10a, c). The maximum of the BC tracer is located near the surface instead of at higher altitudes, and the aerosol does not reach as high as observed. This is probably due to the forest fire emission scheme in FLEXPART, which places the smoke plume directly in the lowest $0-150 \mathrm{~m}$ above ground and relies on turbulent transport and mixing processes to distribute the $\mathrm{CO}$ tracer in the vertical. This procedure likely concentrates the $\mathrm{CO}$ and aerosol near ground level.

In summary, the validation of the horizontal structure of the model simulations provides independent validation of the simulated forest fire plumes. While the vertical altitude of one feature is well simulated, some deficiencies in the vertical distribution of aerosol tracer near the emission source in FLEXPART are identified.

\subsection{Comparison between models and in situ aircraft data}

In-situ CO observations of the NASA aircraft DC-8 during flight 22 on 9 July 2008 allow us to evaluate the validity of the model simulations against an independent data set of insitu observations. The flight data provides local information about the small-scale structure of pollution plumes, the layering, and the strength of gradients. For the comparison, $\mathrm{CO}$ mixing ratios along the flight track have been extracted from the FLEXPART and TOMCAT simulations.

The aircraft flew first over Greenland towards the south for an inter-comparison with the DLR Falcon, then north up to $88^{\circ} \mathrm{N}$, and back to Thule airport (Fig. 11a). Along the way, the aircraft made several profiles to probe the vertical extent of pollution layers (Fig. 11b). During the first leg of the flight, the aircraft encountered moderately polluted layers of around $100-150 \mathrm{ppbv}$ CO mostly at altitudes between 6$8 \mathrm{~km}$ (Fig. 11c, red line). While both models follow the general trend of the aircraft data, both underestimate the variability. A low bias is visible in the TOMCAT data, which appears consistent with the lower background concentrations already identified in Fig. 1b. FLEXPART's tagged tracers indicate that the pollution enhancement at higher altitudes originates from biomass burning, as can be seen from the offset of the solid black line over the gray shaded area. 


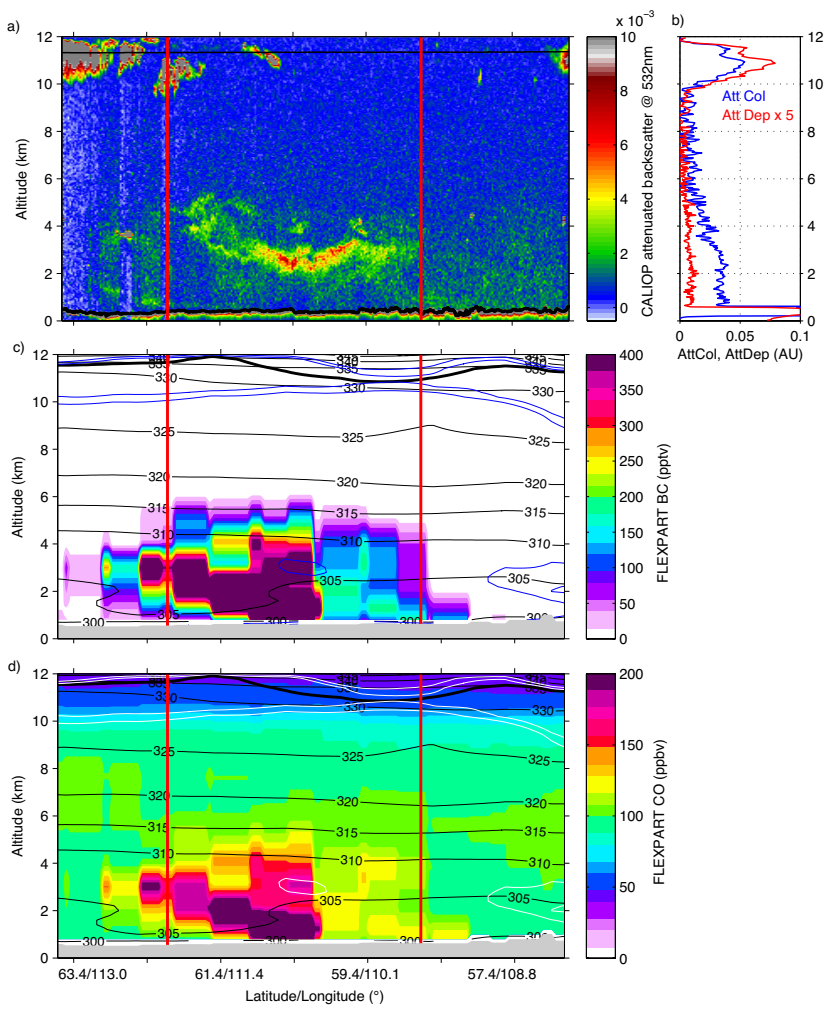

Fig. 10. As Fig. 9, but for an aerosol feature observed on 8 July 2008 19:00 UTC (see Fig. 4c).

As the aircraft is heading north at 15:00 UTC it enters stratospheric air with low CO concentrations. At around 15:45 UTC it abruptly enters an airmass with significantly enhanced pollution levels, reaching up to $240 \mathrm{ppbv} \mathrm{CO}$ at around $8 \mathrm{~km}$ altitude (Fig. 11c). During this part of the flight, both models show very good agreement with the flight data. Drops in pollution levels during downward and upward profiles in the observations and model data indicate that the vertical structure of the pollution is well represented. Some of the $\mathrm{CO}$ enhancement observed by the aircraft originates from biomass burning as identified by FLEXPART's tagged tracers (gray area).

For further comparison, a backward analysis of the DC8 flight was performed using FLEXPART. For the series of backward simulations along the flight track, the model is initialized in a very small volume around every flight position, whereas the forward simulation output is sampled along the flight track at the relatively coarse $0.5^{\circ}$ grid resolution. Thus, a backward simulation takes full advantage of the Lagrangian nature of the model and allows even finerscale structures to be resolved than with the forward simulation, as shown by Stohl et al. (2003). A large number of air parcels $(60000)$ were tracked backwards from locations along the flight track of the aircraft when its position had changed more than $0183^{\circ}$ horizontally or $100 \mathrm{~m}$ vertically.
Emissions in the surface layer were then integrated along the trajectories of the air parcel to construct estimates of $\mathrm{CO}$ concentration. Figure $11 \mathrm{~d}$ compares this backward product for biomass burning emissions and combined anthropogenic and biomass burning emissions to the DC8 CO measurements. It can be seen that a number of the peaks in the observational time series are better matched in the backward product (e.g. near 16:20 UTC or 17:40 UTC) which are due to forest fires. Also, more fine-scale structure is present in the model time series. In a few cases, the backward product is worse than the forward product (e.g. near 14:50 UTC). At $75^{\circ}$ latitude and typical airspeed of the DC-8, the backward run FLEXPART data resolves features of about $10-30 \mathrm{~km}$ width. The $10 \mathrm{~s}$ averaged $\mathrm{CO}$ data from the DC- 8 can resolve features of up to $2.5 \mathrm{~km}$ length. Thus, even with a perfectly simulated advection of the plume, FLEXPART would miss some of the variability measured by the aircraft.

The vertical structure of the pollution is further investigated by a comparison between the vertical $\mathrm{CO}$ curtains from both models along the flight track, and the DIAL aerosol lidar onboard the NASA DC-8 (Fig. 12a). While the aerosol backscatter lidar signal is not directly comparable to the $\mathrm{CO}$ field in the model simulations, it gives some indication of vertical and horizontal positioning of pollution plumes, and the location of maxima. As can be seen most clearly in the TOMCAT and FLEXPART CO mixing ratio curtains (Fig. 12c,e), the aircraft probed two major pollution areas, a first one that is of smaller scale and at altitudes between 6$10 \mathrm{~km}$, on the southern part of the flight track over Greenland (Fig. 11a). Later on a second, broader plume of higher $\mathrm{CO}$ concentrations was reached north of Greenland that also extends over a larger range of altitudes $(4.5-11 \mathrm{~km})$, and was located over the Canadian Arctic (Fig. 11a).

While the location of the maximum of the first feature in terms of altitude and extent agrees well between FLEXPART and the DC- 8 lidar data, the maximum is more diffuse and has a larger horizontal extent in the TOMCAT simulation. As indicated by the relative humidity data from ECMWF (Fig. 12b, blue contours) at least some of the backscatter in the aerosol plot likely originates from clouds. The dynamical tropopause from the ECMWF analysis (thick red line) confirms that the aircraft was located within the stratosphere at around 15:30 UTC.

The second feature, which is delimited towards the south by ice clouds (dark red area in Fig. 12a) is simulated quite differently in terms of $\mathrm{CO}$ structure by the two models. While FLEXPART distributes the $\mathrm{CO}$ pollution roughly co-located with the clouds and down to altitudes of $3 \mathrm{~km}$ (Fig. 12c), in TOMCAT the pollution plume has a core of high values at about $7 \mathrm{~km}$ altitude. As Fig. $11 \mathrm{c}$ demonstrates, both shapes of the plume provide a more or less realistic simulated CO measurement along the DC- 8 flight, even though TOMCAT has a low bias at around 17:00 UTC. Vertical transport in the two models appears to have brought the biomass burning emissions into different atmospheric 

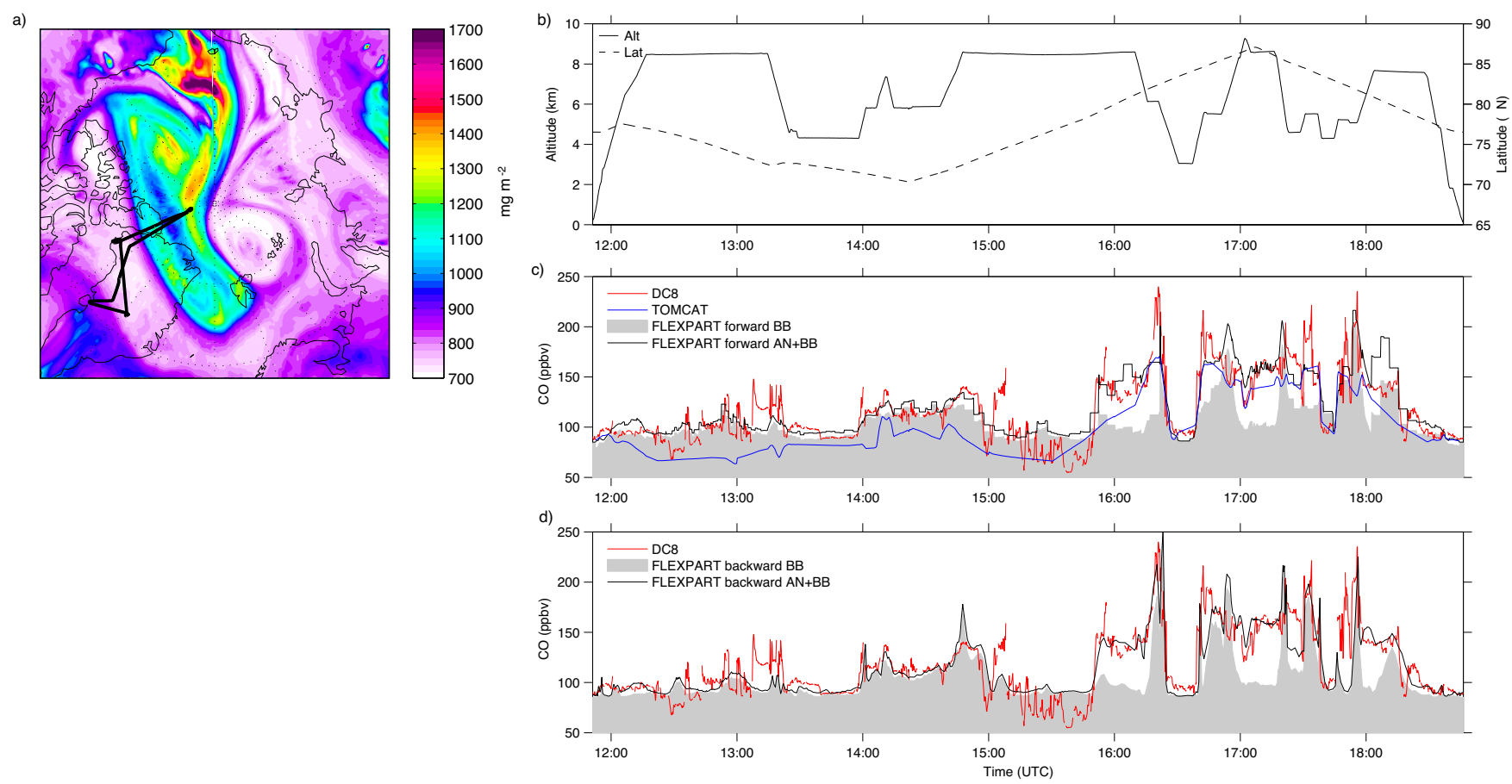

Fig. 11. Flight 22 on 9 July 2008 of the NASA DC-8. (a) Flight track (black line) overlaid on FLEXPART total column CO (mg m ${ }^{-2}$ ) on 9 July 2008 15:00 UTC. Orography has been filled with background CO concentrations to make the plume uniformly visible. (b) Flight altitude from Global Positioning System data (solid line) and latitude (dashed line). (c) CO measurements from the DC-8 (red) compared to FLEXPART biomass burning CO (gray shading), FLEXPART anthropogenic CO (black solid line) and TOMCAT model data (blue line) interpolated to the location of the aircraft in ppbv. (d) CO measurements from the DC-8 (red) compared with backward products of the FLEXPART model for biomass burning CO (gray shading) and combined anthropogenic and biomass burning CO (black line) in ppbv.

layers, and thus the core of the polluted air reaches further down in the FLEXPART simulation (Fig. 12c). Possibly, part of the difference is related to the fact that FLEXPART treats agricultural and wildfires differently, whereas in TOMCAT the emissions are distributed evenly over a day starting at 00:00 UTC. Unfortunately this region was not directly probed by the aircraft. However, the DIAL data and FLEXPART aerosol tracer show a similar upper boundary at $\sim$ 17:00 UTC (Fig. 12a, b).

The black carbon tracer from FLEXPART indicates the presence of some aerosol in both major plumes (Fig. 12b). While in the first plume the aerosol is near the tropopause, the second plume has a simulated aerosol maximum at lower levels. The cloudiness of the scene makes a comparison to the DIAL data difficult. Some of the finer aerosol layers at intermediate levels $6-8 \mathrm{~km}$ that are apparent in the DIAL data between 12:00-16:00 UTC are not simulated by FLEXPART. A separation of the CO enhancement in FLEXPART due to forest fires (Fig. 12d) and Asian anthropogenic emissions (Fig. 12f) highlights that the pollution is vertically stacked, similar to the aerosol mixing ratios: the first plume contains mostly forest fire emissions, while the second plume is of Asian fossil fuel combustion origin above about 6-7 km altitude and of mixed Siberian forest fire and Asian fossil fuel combustion origin below. Thus, during advection the airmass had incorporated other polluted air masses of East Asian (Chinese) origin (Roiger et al., 2011).

\section{Discussion}

\subsection{Transport with Arctic low-pressure systems}

The pollution transport across the North Pole in association with low-pressure systems as shown here suggests that this could be an effective transport mechanism for polluted midlatitude air to the Arctic atmosphere. While it may appear rare to observe two low-pressure systems in the proximity of the North Pole within such a short time period, it is well established that the mean SLP field during northern hemisphere (NH) summer (JJA) has a SLP minimum near $85^{\circ} \mathrm{N}$, $180^{\circ}$ E (Reed and Kunkel, 1960; Serreze and Barrett, 2008). Tracking cyclones in the NCEP (National Center for Environmental Prediction) reanalysis data for the period 19712000, Orsolini and Sorteberg (2009) found that the Arctic SLP minimum is established by about 20 cyclonic systems each season that slow down and finally decay near the central Arctic ocean. Most of these systems originate in a baroclinic zone located along the Eurasian coast that presumably is cre- 

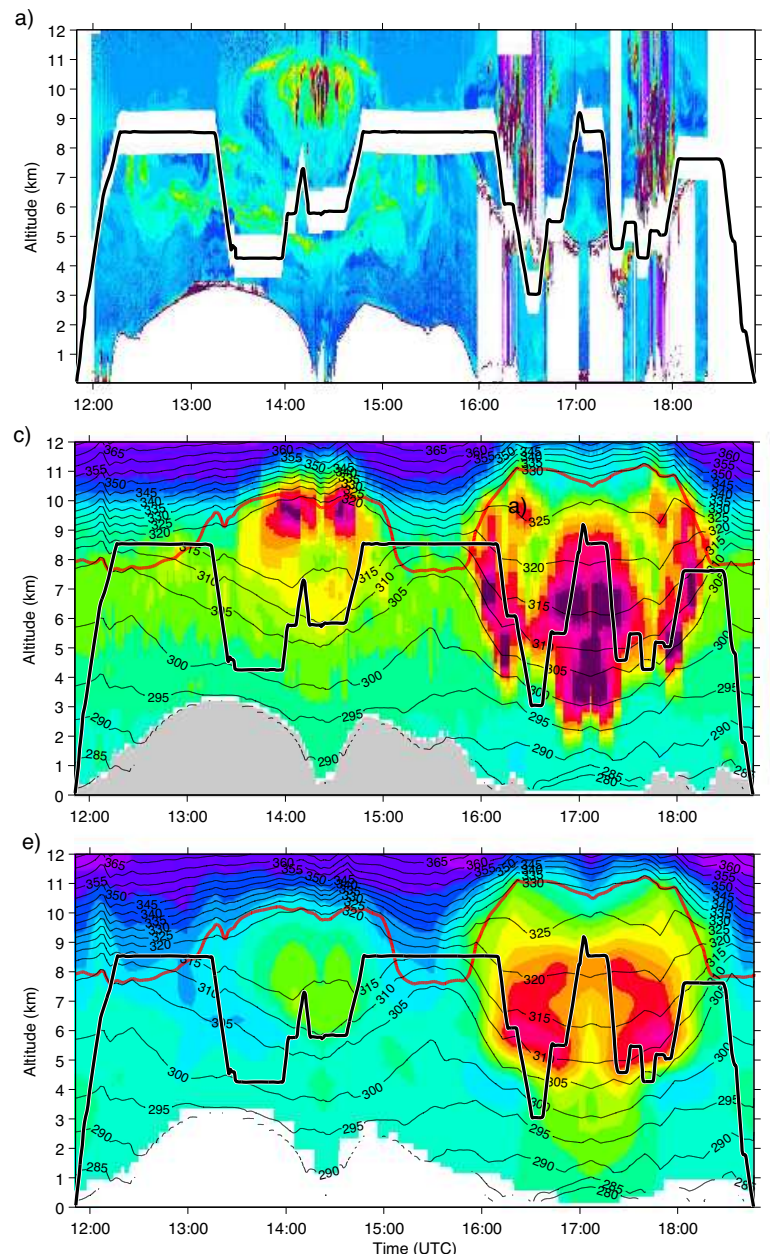

b)

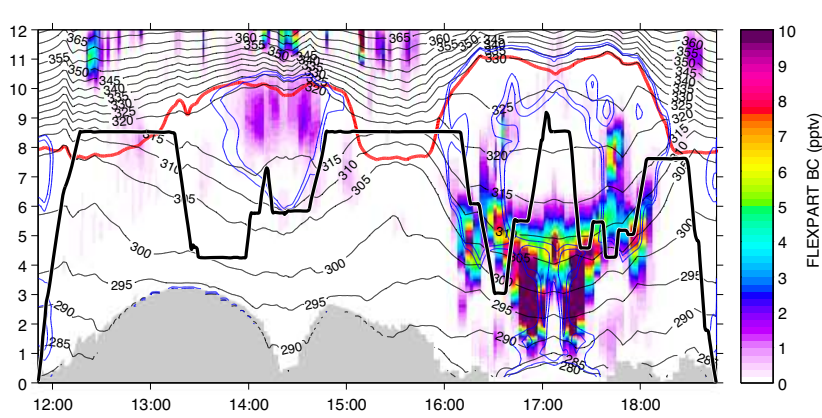

d)

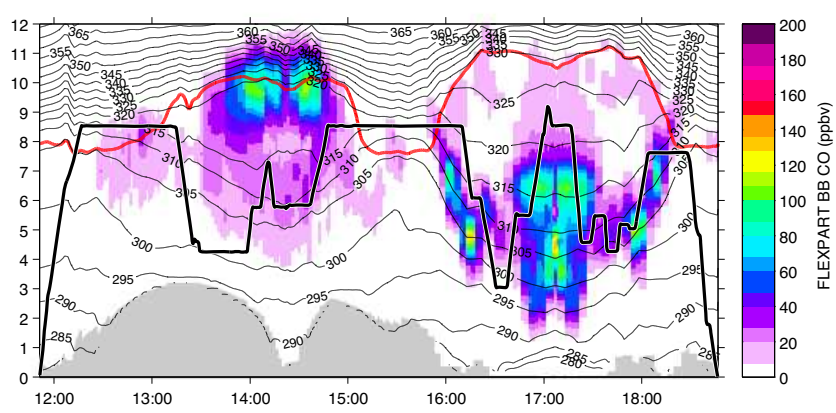

f)

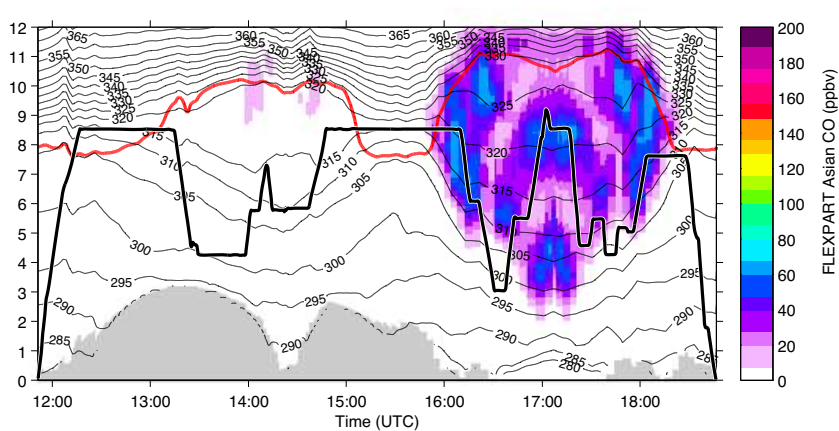

Fig. 12. (a) Aerosol scattering ratio (1064 nm) during DC-8 Flight 22 on 9 July 2008. (b) black carbon curtain (pptv) and (c) total CO curtain (ppbv) from FLEXPART. (d) biomass burning CO tracer (ppbv) from FLEXPART, (e) TOMCAT total CO (ppbv) and (f) Asian CO tracer (ppbv) from FLEXPART. Flight track is shown as thick black line in all panels. Meteorological conditions are indicated by the dynamical tropopause ( 2 pvu, thick red contour, panel b-f), potential temperature (black contours, panel b-f), and relative humidity ( $80 \%$ and $90 \%$, blue contours, panel b) from ECMWF analyses. Orography in each panel is shown according to the respective model's resolution.

ated by the land/ocean temperature contrast in that region during summer (Serreze and Barrett, 2008). The regularity of such cyclones (Orsolini and Sorteberg, 2009) suggests that the transport events studied here may indeed be a common pathway for the transport of Asian forest fire and fossilfuel burning emissions into the Arctic atmosphere during $\mathrm{NH}$ summer. In this context, it appears not unusual that two such events occurred during the two-week period of the POLARCAT summer campaign (1-15 July 2008). Only the second cyclone was unusually strong which allowed it to cross the North Pole and to be still visible as a SLP minimum when being incorporated in the mean westerly flow over Scandinavia.

\subsection{Model TCO biases}

The two transport models have biases compared to the IASI satellite retrievals. FLEXPART has mostly lower background values than the IASI retrieval, while maxima appear overestimated. One possibility for this low bias is that the background profile that was added to the FLEXPART data was too low, since the aircraft data used to construct the background profile was only from a limited domain, that was not representative for the whole Arctic (see Sect. 2.5). For TOMCAT, a general low bias is apparent, which was already observed in Fig. 2, and most likely represents a combination of numerical diffusion and $\mathrm{OH}$ oxidation. For a fair comparison with the satellite data, the model data had to be blended with the kernel and the prior according to Eq. (1). As was shown in Fig. 8c, applying the IASI AKs transforms the concentration field of the models nonlinearly. As can be seen 
in Fig. 1a, IASI is most sensitive to the CO concentration at 200-400 hPa, while surface data are mostly determined by the a priori. In addition, at vertical altitudes above $300 \mathrm{hPa}$ the discrepancy between the IASI a priori and the model background reaches its maximum (Fig. 1b). Possibly, the choice of a globally applicable a priori profile that does not take into account the low tropopause height in polar regions causes a high bias for high latitude retrievals. Note also that due to the AK weighting model differences at lower levels are obscured in a TCO comparison. Models transport a large portion of the $\mathrm{CO}$ at altitudes where IASI is less sensitive, and thus when weighted with IASI AKs this is replaced by a priori values.

Due to the economic development in East Asia in recent years, emissions from fossil-fuel burning have increased tremendously, maybe even doubled (Zhang et al., 2009), since the year 2000 (the current updating status of the EDGAR emissions inventory). The DC8 was sampling North American air for the first half of its flight on 9 July 2008. After 16:00 UTC, it sampled air masses with Asian origin (Fig. 12f). The low bias for TOMCAT is stronger in the North American air for TOMCAT, but not for FLEXPART (Fig. 11b). As Shindell et al. (2008) concluded, in fact most current CTMs have a CO low bias in the Arctic. In the Asian air, the peaks are underestimated. This could be an indication that Asian emissions are indeed underestimated. For FLEXPART it is less of a problem to match the baseline since this is at least partly incorporated in the background profile.

Further validation studies of the IASI data using in situ aircraft profile data underneath the satellite show that below $8 \mathrm{~km}$, retrieved IASI profiles are biased high compared to smoothed profiles from in situ measurements for polluted cases during the summer of 2008 (Pommier et al., 2010). Comparing $\mathrm{CO}$ in the GEOS-Chem CTM and the AIRS satellite Fisher et al. (2010) also noted a consistent high bias of the satellite data. In that case however, the high bias of the AIRS data is probably induced by the operational retrieval method (Warner et al., 2010).

One possibility for a high bias of the IASI retrievals could be that in general the atmospheric $\mathrm{CO}$ enhancements are located at fairly high altitudes, where IASI has good sensitivity. The retrieval algorithm accordingly tries to capture the enhancement by departing from the prior. It probably does well in the free troposphere, but because the sensitivity in the lowest layers is close to zero, this also translates to higher concentrations near the surface. In other words the entire profile is scaled to catch the free tropospheric enhancements, and then the resulting total CO column is too high.

\subsection{Model-data comparison}

The present flight data does not allow for a final evaluation of which kind of model is most realistic. However, taking into account the overall information gained from the multi-data comparison of both model simulations allows a better or more informed understanding of along-flight $\mathrm{CO}$ data extracted from a Lagrangian or an Eulerian model. The prime difference between the two kinds of models is the impact of numerical diffusion and the preservation of gradients. As convincingly demonstrated by the IASI satellite observations, fine filaments are created from larger plumes over the course of several days with high gradients that can not be simulated by coarse resolution models. Lagrangian models do retain these gradients. This is particularly relevant in the polar atmosphere, where due to the strong atmospheric stability stirring generally is more important than mixing. Nevertheless, it should be emphasised that the advection of a fine-scale structure directly across the pole can be seen as the most difficult test case for an Eulerian model, and in this context the results from the TOMCAT model can be considered as encouraging.

A drawback in Lagrangian models without full chemistry is that they need a background value for atmospheric constituents beyond the transport time scale, which is a nontrivial choice, and could introduce a bias. Chemical transformations, in particular loss of $\mathrm{CO}$ due to $\mathrm{OH}$ are typically not included in such simulations, such as the FLEXPART simulation used here. Further aspects that are relevant are the vertical structure of plumes as they are emitted. Aircraft typically observe much smaller filaments than simulated by any model. The variability seen in an aircraft measurement is thus difficult to reproduce in any model without the inclusion of further subgrid-scale processes that would take into account non-homogeneous tracer distribution.

Most CTMs point to Asia as the largest pollution source at higher altitudes (500-250 hPa) in the Arctic (Shindell et al., 2008; Koch and Hansen, 2005). But even in the lower troposphere of the Arctic CTMs have a higher Asian contribution to the overall pollution (e.g. Koch and Hansen, 2005; Fisher et al., 2010) than indicated by Lagrangian model (Stohl, 2006). Given the findings from the present study, it is likely that numerical effects, such as the larger horizontal and in particular vertical resolution in Eulerian CTMs compared to the (maybe overly) sharp concentration gradients in a Lagrangian model contribute to the difference of simulation results from both model types.

\section{Conclusions}

The main conclusions from comparing the two conceptually very different atmospheric transport model simulations with observational data for a period during July 2008 are that (i) in general, both model simulations driven by the same meteorological fields (even though at different resolutions) agree remarkably well for features of sufficient size. (ii) Pollution features that cannot be sufficiently resolved on the grid of an Eulerian model disperse too quickly, whereas gradients are well preserved by the Lagrangian model. (iii) It is essential for a meaningful interpretation to consider the effect of the 
averaging kernels on the simulated retrievals when comparing the models with satellite observations.

Retrieved values of TCO from the IASI satellite allow us to validate the spatial extent and structure of pollution plumes as simulated by the models. In the configuration applied here, the FLEXPART model could realistically resolve pollution features up to a horizontal width of $\sim 100$ $250 \mathrm{~km}$. While the coarser-grid model TOMCAT could not resolve such narrow features, correspondence between both models and the satellite data was excellent for structures of $\sim 850 \mathrm{~km}$ horizontal width or more. Comparison with aircraft in situ data shows that the vertical structure of for example aerosols may depend on the parameterisation scheme of forest fire emissions in FLEXPART either with respect to height or magnitude or both.

Even with the rich data set at hand in this study, it is non-trivial to find a reference observation against which the model results can be compared. Satellite observations provided good spatial coverage, but were limited in vertical resolution, in particular in the Arctic region due to the low temperatures prevailing. In addition, satellite retrievals were only sensitive within certain atmospheric layers as reflected by the averaging kernel. The choice of the a priori may hence have a large influence on all retrievals. Nonetheless it was crucial when comparing model simulations to satellite data to apply the prior to the models as well. Specifically adapted a priori profiles, e.g. dependent on latitude and season, could help to reduce potential biases in the satellite data.

While numerical issues had a visible impact on model results, and may need further attention or should at least be kept in mind when comparing models to observations, the general level of agreement between the model simulations and observations was quite impressive and strengthens the basis for using such model data in large-scale observation campaigns. When integrating over longer time scales, however, it is conceivable that even small numerical inaccuracies due to overly strong diffusion could influence large-scale concentration gradients to a noticeable degree.

It appears therefore beneficial to compare Lagrangian and Eulerian model results while being aware of the specific numerical effects of a coarse-grid model. Until a Lagrangian CTM is available that is able to reliable simulate mixing and chemical processes, a combination of the information from both kinds of models appears most useful in analysing in situ and remote sensing observational data.

Acknowledgements. Funding for this study was provided by the Norwegian Research Council through the POLARCAT project. This is a contribution to the NASA ARCTAS science mission. The Norwegian Meteorological Service kindly provided access to the ECMWF data. Partial funding was provided by the SatLuft project (ESA PRODEX contract C90283). Thanks to EUFAR for funding the participation of SRA and SAM in the POLARCAT/ArcDAT campaign. IASI has been developed and built under the responsibility of the Centre National des Etudes Spatiales (CNES). It is flown onboard the MetOp-A satellite as part of the
Eumetsat Polar system. The IASI L1 data are received through the Eumetcast near real time data distribution service. IASI L1 and L2 data are stored in the Ether French atmospheric database (http://ether.ipsl.jussieu.fr). MP has been supported by a grant from CNES and from NOVELTIS. The research in Belgium was funded by the F.R.S.-FNRS (M.I.S. nF.4511.08), the Belgian State Federal Office for Scientific, Technical and Cultural Affairs and the European Space Agency (ESA-Prodex arrangements C90-327). Financial support by the Communauté française de Belgique Actions de Recherche Concertées is also acknowledged. CALIPSO data were obtained from the Atmospheric Sciences Data Center at NASA Langley Research Center. We thank M. P. Chipperfield for helpful comments on an earlier version of this manuscript. Two anonymous reviewers are acknowledged for their thorough and constructive reviews.

Edited by: P. Monks

\section{References}

Andreae, M. and Merlet, P.: Emission of trace gases and aerosols from biomass burning, Global Biogeochem. Cy., 15, 955-966, 2001.

Arnold, S. R., Chipperfield, M. P., and Blitz, M. A.: A threedimensional model study of the effect of new temperaturedependent quantum yields for acetone photolysis, J. Geophys. Res., 110, D22305, doi:10.1029/2005JD005998, 2005.

Barrie, L. A.: Arctic air pollution: an overview of current knowledge, Atmos. Environ., 20, 643-663, 1986.

Bey, I., Jacob, D., Yantosca, R., Logan, J., Field, B., Fiore, A., Li, Q., Liu, H., Mickley, L., and Schultz, M.: Global modeling of tropospheric chemistry with assimilated meteorology: Model description and evaluation, J. Geophys. Res., 106, 23073-23095.

Browell, E., Ismail, S., and Grant, W.: Differential absorption lidar (DIAL) measurements from air and space, Appl. Phys. B-Lasers O, 67, 399-410, 1998.

Chipperfield, M., Feng, W., and Rex, M.: Arctic ozone loss and climate sensitivity: Updated three-dimensional model study, Geophys. Res. Lett., 32, L11813, doi:10.1029/2005GL022674, 2005.

Chipperfield, M. P.: New version of the TOMCAT/SLIMCAT off-line chemical transport model: Intercomparison of stratospheric tracer experiments, Q. J. Roy. Meteorol. Soc., 132, 1179, doi:10.1256/qj.05.51, 2006.

Clerbaux, C., Boynard, A., Clarisse, L., George, M., Hadji-Lazaro, J., Herbin, H., Hurtmans, D., Pommier, M., Razavi, A., Turquety, S., Wespes, C., and Coheur, P.-F.: Monitoring of atmospheric composition using the thermal infrared IASI/MetOp sounder, Atmos. Chem. Phys., 9, 6041-6054, doi:10.5194/acp-9-6041-2009, 2009.

Emmons, L. K., Walters, S., Hess, P. G., Lamarque, J.-F., Pfister, G. G., Fillmore, D., Granier, C., Guenther, A., Kinnison, D., Laepple, T., Orlando, J., Tie, X., Tyndall, G., Wiedinmyer, C., Baughcum, S. L., and Kloster, S.: Description and evaluation of the Model for Ozone and Related chemical Tracers, version 4 (MOZART-4), Geosci. Model Dev., 3, 43-67, doi:10.5194/gmd3-43-2010, 2010.

Engvall, A.-C., Krejci, R., Strom, J., Minikin, A., Treffeisen, R., Stohl, A., and Herber, A.: In-situ airborne observations of the microphysical properties of the Arctic tropospheric 
aerosol during late spring and summer, Tellus B, 60, 392-404, doi:10.1111/j.1600-0889.2008.00348.x, 2008.

Engvall, A.-C., Strom, J., Tunved, P., Krejci, R., Schlager, H., and Minikin, A.: The radiative effect of an aged, internally mixed Arctic aerosol originating from lower-latitude biomass burning, Tellus B, 61, 677-684, doi:10.1111/j.1600-0889.2009.00431.x, 2009.

Feitas, S. R., Longo, K. M., Dias, M. A. S., Dias, P. L. S., Chatfield, R., Prins, E., Artaxo, P., Grell, G. A., and Recuero, F. S.: Monitoring the transport of biomass burning emissions in South America, Environ. Fluid Mech., 5, 135-167, 2005.

Fisher, J. A., Jacob, D. J., Purdy, M. T., Kopacz, M., Le Sager, P., Carouge, C., Holmes, C. D., Yantosca, R. M., Batchelor, R. L., Strong, K., Diskin, G. S., Fuelberg, H. E., Holloway, J. S., Hyer, E. J., McMillan, W. W., Warner, J., Streets, D. G., Zhang, Q., Wang, Y., and Wu, S.: Source attribution and interannual variability of Arctic pollution in spring constrained by aircraft (ARCTAS, ARCPAC) and satellite (AIRS) observations of carbon monoxide, Atmos. Chem. Phys., 10, 977-996, doi:10.5194/acp-10-977-2010, 2010.

George, M., Clerbaux, C., Hurtmans, D., Turquety, S., Coheur, P.F., Pommier, M., Hadji-Lazaro, J., Edwards, D. P., Worden, H., Luo, M., Rinsland, C., and McMillan, W.: Carbon monoxide distributions from the IASI/METOP mission: evaluation with other space-borne remote sensors, Atmos. Chem. Phys., 9, 8317-8330, doi:10.5194/acp-9-8317-2009, 2009.

Gerbig, C., Schmitgen, S., Kley, D., Volz-Thomas, A., Dewey, K., and Haaks, D.: An improved fast-response vacuum-UV resonance fluorescence CO instrument, J. Geophys. Res., 104, 16991704, 1999.

Grell, G., Peckham, S., Schmitz, R., McKeen, S., Frost, G., Skamarock, W., and Eder, B.: Fully coupled "online" chemistry within the WRF model, Atmos. Environ., 39, 6957-6975, doi:10.1016/j.atmosenv.2005.04.027, 2005.

Guenther, A., Karl, T., Harley, P., Wiedinmyer, C., Palmer, P. I., and Geron, C.: Estimates of global terrestrial isoprene emissions using MEGAN (Model of Emissions of Gases and Aerosols from Nature), Atmos. Chem. Phys., 6, 3181-3210, doi:10.5194/acp-63181-2006, 2006.

Holtslag, A. A. M. and Boville, B.: Local versus nonlocal boundary-layer diffusion in a global climate model, J. Climate, 6, 1825-1842, 1993.

Klonecki, A., Hess, P., Emmons, L., Smith, L., Orlando, J., and Blake, D.: Seasonal changes in the transport of pollutants into the Arctic troposphere-model study, J. Geophys. Res., 108, 8367, doi:10.1029/2002JD002199, 2003.

Koch, D. and Hansen, J.: Distant origins of Arctic black carbon: A Goddard Institute for Space Studies ModelE experiment, J. Geophys. Res., 110, D04204, doi:10.1029/2004JD005296, 2005.

Krol, M., Houweling, S., Bregman, B., van den Broek, M., Segers, A., van Velthoven, P., Peters, W., Dentener, F., and Bergamaschi, P.: The two-way nested global chemistry-transport zoom model TM5: algorithm and applications, Atmos. Chem. Phys., 5, 417432, doi:10.5194/acp-5-417-2005, 2005.

Lamarque, J.-F., Bond, T. C., Eyring, V., Granier, C., Heil, A., Klimont, Z., Lee, D., Liousse, C., Mieville, A., Owen, B., Schultz, M. G., Shindell, D., Smith, S. J., Stehfest, E., Van Aardenne, J., Cooper, O. R., Kainuma, M., Mahowald, N., McConnell, J. R., Naik, V., Riahi, K., and van Vuuren, D. P.: His- torical (1850-2000) gridded anthropogenic and biomass burning emissions of reactive gases and aerosols: methodology and application, Atmos. Chem. Phys., 10, 7017-7039, doi:10.5194/acp10-7017-2010, 2010.

Liu, Z., Vaughan, M., Winker, D., Hostetler, C., Poole, L., Hlavka, D., Hart, W., and McGill, M.: Use of probability distribution functions for discriminating between cloud and aerosol in lidar backscatter data, J. Geophys. Res., 109, D15202, doi:10.1029/2004JD004732, 2004.

Liu, Z., Vaughan, M., Winker, D., Kittaka, C., Getzewich, B., Kuehn, R., Omar, A., Powell, K., Trepte, C., and Hostetler, C.: The CALIPSO Lidar Cloud and Aerosol Discrimination: Version 2 Algorithm and Initial Assessment of Performance, J. Atmos. Ocean. Techn., 26, 1198-1213, doi:10.1175/2009JTECHA1229.1, 2009.

Longo, K. M. and Feitas, S. R.: Estimation of biomass burning emissions on South America using field observations and remote sensing, Proceedings of 8 ICSHMO, Foz do Iguacu, Brazil, 2428 April, 2006, INPE, 115-119, 2007.

Madronich, S.: Photodissociation in the atmosphere: 1. Actinic flux and the effects of ground reflections and clouds, J. Geophys. Res., 92, 9740-9752, 1987.

Monks, S. A., Arnold, S. R., Chipperfield, M. P., Richards, N., Law, K., Schlager, H., Paris, J.-D., Turquety, S., Weidinmyer, C., and Emmons, L.: Evaluation of boreal forest fire emission estimates and impacts on Arctic atmospheric composition during summer 2008, in preparation, 2011.

Olivier, J. G. J. and Berdowski, J. J. M.: Global emissions sources and sinks, in: The Climate System, edited by: Berdowski, J., Guicherit, R., and Heij, B. J., A.A. Balkema Publishers/Swets\&Zeitlinger Publishers, Lisse, The Netherlands, ISBN 905809255 0, 33-78, 2001.

Orsolini, Y. J. and Sorteberg, A.: Projected changes in Eurasian and Arctic summer cyclones under global warming in the Bergen Climate Model, Atmos. Ocean. Sci. Lett., 2, 62-67, 2009.

Paris, J.-D., Stohl, A., Nédélec, P., Arshinov, M. Yu., Panchenko, M. V., Shmargunov, V. P., Law, K. S., Belan, B. D., and Ciais, P.: Wildfire smoke in the Siberian Arctic in summer: source characterization and plume evolution from airborne measurements, Atmos. Chem. Phys., 9, 9315-9327, doi:10.5194/acp-9-9315-2009, 2009.

Pommier, M., Law, K. S., Clerbaux, C., Turquety, S., Hurtmans, D., Hadji-Lazaro, J., Coheur, P.-F., Schlager, H., Ancellet, G., Paris, J.-D., Nédélec, P., Diskin, G. S., Podolske, J. R., Holloway, J. S., and Bernath, P.: IASI carbon monoxide validation over the Arctic during POLARCAT spring and summer campaigns, Atmos. Chem. Phys. Discuss., 10, 14445-14494, doi:10.5194/acpd-1014445-2010, 2010.

Prather, M.: Numerical advection by conservation of 2nd-order moments, J. Geophys. Res., 91, 6671-6681, 1986.

Prather, M., McElroy, M., Wofsy, S., Russell, G., and Rind, D.: Chemistry of the global troposphere - fluorocarbons as tracers of air motion, J. Geophys. Res., 92, 6579-6613, 1987.

Raatz, W. and Shaw, G.: Long-range tropospheric transport of pollution aerosols into the Alaskan Arctic, J. Clim. Appl. Meteorol., 23, 1052-1064, 1984.

Rastigejev, Y., Park, R., Brenner, M., and Jacob, D.: Resolving intercontinental pollution plumes in global models of atmospheric transport, J. Geophys. Res., 115, D02302, 
doi:10.1029/2009JD012568, 2010.

Reed, R. J. and Kunkel, B. A.: The Arctic circulation in summer, J. Atmos. Sci., 17, 489, doi:10.1175/15200469(1960)017;0489:TACIS $; 2.0 . C O ; 2,1960$.

Rodgers, C.: Inverse methods for atmospheric sounding: theory and practice, Ser. Atmos. Ocean. Planet. Phys Vol. 2, World Science, Hackensack, NJ, USA, 2000.

Roiger, A., Schlager, H., Schfler, A., Huntrieser, H., Scheibe, M., Aufmhoff, H., Cooper, O. R., Lazzara, M., Stohl, A., Sodemann, H., Burkhart, J., Schiller, C., Law, K., Pommier M., and Arnold F.: In-situ observation of Asian pollution transported into the Arctic lowermost stratosphere, Atmos. Chem. Phys. Discuss., to be submitted, 2011.

Sachse, G., Hill, G., Wade, L. O., and Perry, M. G.: Fast-response, high-precision carbon-monoxide sensor using a tunable diodelaser absorption technique, J. Geophys. Res., 92, 2071-2081, 1987.

Serreze, M. C. and Barrett, A. P.: The summer cyclone maximum over the central Arctic ocean, J. Climate, 21, 1048, doi:10.1175/2007JCLI1810.1, 2008.

Shindell, D. T., Chin, M., Dentener, F., Doherty, R. M., Faluvegi, G., Fiore, A. M., Hess, P., Koch, D. M., MacKenzie, I. A., Sanderson, M. G., Schultz, M. G., Schulz, M., Stevenson, D. S., Teich, H., Textor, C., Wild, O., Bergmann, D. J., Bey, I., Bian, H., Cuvelier, C., Duncan, B. N., Folberth, G., Horowitz, L. W., Jonson, J., Kaminski, J. W., Marmer, E., Park, R., Pringle, K. J., Schroeder, S., Szopa, S., Takemura, T., Zeng, G., Keating, T. J., and Zuber, A.: A multi-model assessment of pollution transport to the Arctic, Atmos. Chem. Phys., 8, 5353-5372, doi:10.5194/acp-8-5353-2008, 2008.

Sodemann, H., Pommier, M., Arnold, S. R., Monks, S. A., Stebel, K., Burkhart, J. F., Hair, J. W., Diskin, G. S., Clerbaux, C., Coheur, P.-F., Hurtmans, D., Schlager, H., Blechschmidt, A.-M., Kristjnsson, J. E., and Stohl, A.: Episodes of cross-polar transport in the Arctic troposphere during July 2008 as seen from models, satellite, and aircraft observations, Atmos. Chem. Phys. Discuss., 10, 26361-26410, doi:10.5194/acpd-10-26361-2010, 2010.

Stockwell, W., Middleton, P., Chang, J., and Tang, X.: The 2nd generation regional acid deposition model chemical mechanism for regional air-quality modeling, J. Geophys. Res., 95, 1634316367, 1990.

Stohl, A.: Characteristics of atmospheric transport into the Arctic troposphere, J. Geophys. Res., 111, D11306, doi:10.1029/2005JD006888, 2006.

Stohl, A., Forster, C., Eckhardt, S., Spichtinger, N., Huntrieser, H., Heland, J., Schlager, H., Wilhelm, S., Arnold, F., and Cooper, O.: A backward modeling study of intercontinental pollution transport using aircraft measurements, J. Geophys. Res., 108, 4370, doi:10.1029/2002JD002862, 2003.

Stohl, A., Forster, C., Frank, A., Seibert, P., and Wotawa, G.: Technical note: The Lagrangian particle dispersion model FLEXPART version 6.2, Atmos. Chem. Phys., 5, 2461-2474, doi:10.5194/acp-5-2461-2005, 2005.

Stohl, A., Berg, T., Burkhart, J. F., Fjǽraa, A. M., Forster, C., Herber, A., Hov, Ø., Lunder, C., McMillan, W. W., Oltmans, S., Shiobara, M., Simpson, D., Solberg, S., Stebel, K., Ström, J., Trseth, K., Treffeisen, R., Virkkunen, K., and Yttri, K. E.: Arctic smoke record high air pollution levels in the European Arctic due to agricultural fires in Eastern Europe in spring 2006, Atmos. Chem. Phys., 7, 511-534, doi:10.5194/acp-7-511-2007, 2007.

Strunin, M., Postnov, A., and Mezrin, M.: Meteorological potential for contamination of arctic troposphere: Boundary layer structure and turbulent diffusion characteristics, Atmos. Res., 44, 37 $51,1997$.

Thuburn, J.: A PV-based shallow-water model on a hexagonalicosahedral grid, Mon. Weather Rev., 125, 2328-2347, 1997.

Tiedtke, M.: A comprehensive mass flux scheme for cumulus parameterization in large-scale models, Mon. Weather Rev., 117, 1779-1800, 1989.

Turquety, S., Hurtmans, D., Hadji-Lazaro, J., Coheur, P.-F., Clerbaux, C., Josset, D., and Tsamalis, C.: Tracking the emission and transport of pollution from wildfires using the IASI CO retrievals: analysis of the summer 2007 Greek fires, Atmos. Chem. Phys., 9, 4897-4913, doi:10.5194/acp-9-4897-2009, 2009.

Wang, K., Pyle, J., Sanderson, M., and Bridgeman, C.: Implementation of a convective atmospheric boundary layer scheme in a tropospheric chemistry transport model, J. Geophys. Res., 104, 23729-23745, 1999.

Warneke, C., Bahreini, R., Brioude, J., Brock, C. A., de Gouw, J. A., Fahey, D. W., Froyd, K. D., Holloway, J. S., Middlebrook, A., Miller, L., Montzka, S., Murphy, D. M., Peischl, J., Ryerson, T. B., Schwarz, J. P., Spackman, J. R., and Veres, P.: Biomass burning in Siberia and Kazakhstan as an important source for haze over the Alaskan Arctic in April 2008, Geophys. Res. Lett., 36, 02813, doi:10.1029/2008GL036194, 2009.

Warneke, C., Froyd, K. D., Brioude, J., Bahreini, R., Brock, C. A., Cozic, J., de Gouw, J. A., Fahey, D. W., Ferrare, R., Holloway, J. S., Middlebrook, A. M., Miller, L., Montzka, S., Schwarz, J. P., Sodemann, H., Spackman, J. R., and Stohl, A. An important contribution to springtime Arctic aerosol from biomass burning in Russia, Geophys. Res. Lett., 37, 01801, doi:10.1029/2009GL041816, 2010.

Warner, J. X., Wei, Z., Strow, L. L., Barnet, C. D., Sparling, L. C., Diskin, G., and Sachse, G.: Improved agreement of AIRS tropospheric carbon monoxide products with other EOS sensors using optimal estimation retrievals, Atmos. Chem. Phys., 10, 95219533, doi:10.5194/acp-10-9521-2010, 2010.

Wiedinmyer, C., Quayle, B., Geron, C., Belote, A., McKenzie, D., Zhang, X., O’Neill, S., and Wynne, K. K.: Estimating emissions from fires in North America for air quality modeling, Atmos. Environ., 40, 3419-3432, doi:10.1016/j.atmosenv.2006.02.010, 2006.

Winker, D. M., Vaughan, M. A., Omar, A., Hu, Y., Powell, K. A., Liu, Z., Hunt, W. H., and Young, S. A.: Overview of the CALIPSO Mission and CALIOP Data Processing Algorithms, J. Atmos. Ocean. Tech., 26, 2310-2323, doi:10.1175/2009JTECHA1281.1, 2009.

Zhang, Q., Streets, D. G., Carmichael, G. R., He, K. B., Huo, H., Kannari, A., Klimont, Z., Park, I. S., Reddy, S., Fu, J. S., Chen, D., Duan, L., Lei, Y., Wang, L. T., and Yao, Z. L.: Asian emissions in 2006 for the NASA INTEX-B mission, Atmos. Chem. Phys., 9, 5131-5153, doi:10.5194/acp-9-5131-2009, 2009. 